\title{
A review on polymer, gas, surfactant and nanoparticle adsorption modeling in porous media
}

\author{
Isah Mohammed, Clement C. Afagwu, Stephen Adjei, Ibrahim B. Kadafur, Mohammad S. Jamal, \\ and Abeeb A. Awotunde* \\ College of Petroleum Engineering \& Geosciences, King Fahd University of Petroleum \& Minerals, Dhahran 31261, KSA
}

Received: 2 May 2020 / Accepted: 7 August 2020

\begin{abstract}
Adsorption is a rock surface phenomenon and has increasingly become popular, especially in particle-transport applications across many fields. This has drawn a remarkable number of publications from the industry and academia in the last decade, with many review articles focused on adsorption of polymers, surfactants, gas, and nanoparticles in porous media with main applications in Enhanced Oil Recovery (EOR). The discussions involved both experimental and modeling approaches to understanding and efficiently mimicking the particle transport in a bid to solve pertinent problems associated with particle retention on surfaces. The governing mechanisms of adsorption and desorption constitute an area under active research as many models have been proposed but the physics has not been fully honored. Thus, there is a need for EsXMLcontinuous research effort in this field. Although adsorption/desorption process is a physical phenomenon and a reversible process resulting from inter-molecular and the intramolecular association between molecules and surfaces, modeling these phenomena requires molecular level understanding. For this reason, there is a wide acceptance of molecular simulation as a viable modeling tool among scientists in this area. This review focuses on existing knowledge of adsorption modeling as it relates to the petroleum industry cutting across flow through porous media and EOR mostly involving polymer and surfactant retention on reservoir rocks with the associated problems. The review also analyzes existing models to identify gaps in research and suggest some research directions to readers.
\end{abstract}

\section{Introduction}

Adsorption is a surface phenomenon that involves the retention of molecules on surfaces and has been a subject of discussion for decades. In addition, this mechanism is as a result of surface interaction between flowing fluid and the porous media at various scales ranging from micrometer to nanoscale transport in shale formations (An et al., 2017). Several researchers (Joekar-Niasar et al., 2019; Liu et al., 2006; Ogunberu and Asghari, 2005; Yin et al., 2009; Yu et al., 2012; Zhang et al., 2015) have investigated the mechanism of adsorption and have identified the dominant influences on fluid storage in porous media. Rocks due to their mineralogy are pervasive and the modeling of such a system is difficult as a result of the ionic, hydrodynamic, and electrochemical interactions (JoekarNiasar et al., 2019). Furthermore, different from the popular flow assurance adsorption is the surface storage capacity of gases in shale reservoirs which is natural and can be quantified using the simplified and isothermal local density method (Zhang et al., 2019).

\footnotetext{
* Corresponding author: awotunde@kfupm.edu.sa
}

The mechanism of adsorption does not involve the explicit "site" on a grain surface at which a particle can attach but an area phenomenon that covers the entire pore space in time and space. Hence, the specific surface area of a porous medium is expected to have an order of influence. Deem and Ali (1968) studied the effect of the radioactivity of tracers in porous media with the conclusion that preferential adsorption is observed for tracers of similar properties which is due to mineralogy, surface activeness, and concentration. Some experimental and numerical modeling of the phenomena has been carried out by researchers to establish the governing mechanism for particle adsorption at micro, nano and pore scale.

This review article explores the mechanisms, models and applications that have been achieved thus far in the field of adsorption as it concerns the petroleum industry. With the increasing use of nanoparticles in the oil/gas industry specifically in areas such as drilling, exploration and Enhanced Oil Recovery (EOR), it is important to understand the phenomena of adsorption in the porous media. Section 2 of this review attempts to provide insights into the mathematical modeling and experimental studies conducted on nanoparticle adsorption. Section 3, studies the 
adsorption of polymer on rock surfaces. Polymer flooding uses polymer solutions to increase oil recovery by increasing the viscosity of injected water. The increased viscosity decreases the water-oil mobility ratio and provides better sweep efficiency. The injected polymer gets adsorbed on the surface of the rocks and swells leading to pore throat reduction therefore decreasing the permeability of the reservoir rocks. Langmuir adsorption isotherm is the most commonly used method to model adsorption of polymers on rock surfaces. In Section 4 we have reviewed the different adsorption isotherms used to model adsorption of gases in porous media. It is important to accurately model gas adsorption as $20-80 \%$ of shale gas is stored under adsorbed condition (Xiao-Chun et al., 1995). The gas adsorption isotherms can be classified under two broad subheadings: (1) monolayered and multilayered isotherms (Sect. 4.1), and (2) single component and multicomponent isotherms (Sect. 4.2). Finally, in Section 5 we have reviewed the adsorption of surfactants in porous media. Surfactant flooding reduces the interfacial tension and assists in oil recovery. However the adsorption of surfactant on the rock surfaces produces a challenge as the reduced concentration leads to a decrease in the EOR efficiency (Curbelo et al., 2020). Since surfactants account for a large part of the total cost of surfactant injection, their losses also lead to substantial economic losses (Belhaj et al., 2020).

\section{Nanoparticle adsorption}

Nanoparticles (approx. 5-50 $\mathrm{nm}$ ) easily pass through typical reservoir pore throats. However, as a result of the physicochemical attraction between the pore walls and nanoparticles, particle retention is a possibility. The chances of attachment of the molecules to the walls are high with increase in particle transport velocity that is required to push the particles through a pore throat. Interestingly, the motion speed is a function of the molecule size and asperity height. The scale of reference as shown in Figure 1 can range from macro to Nanoscale in adsorption studies.

Zhang et al. (2015) reported an investigation into the adsorption of nanoparticles of silica and iron oxide of varying surface coating on porous media. The authors established the mechanism of nanoparticle retention by varying the flow properties and conditions of flow. Meanwhile, a sand pack column and consolidated sedimentary rock core of varying particle sizes was utilized as a porous media. The findings reveal that there is possibility for a reversible and irreversible adsorption of nanoparticles on the surfaces, owing to changes in interactions between the nanoparticles and the grain surfaces of the rock. The identified mechanism for such behavior is physicochemical interactions which include particle-surface interactions, thermodynamic and hydrodynamic forces, and particle media collision. Furthermore, the effect of electrostatic interactions as a function of salinity results in a strong repulsion between nanoparticles and surfaces with low salinity. A monolayer adsorption behavior is observed when the effluent concentration approaches the injection concentration during the experiment. To account for the desorption of

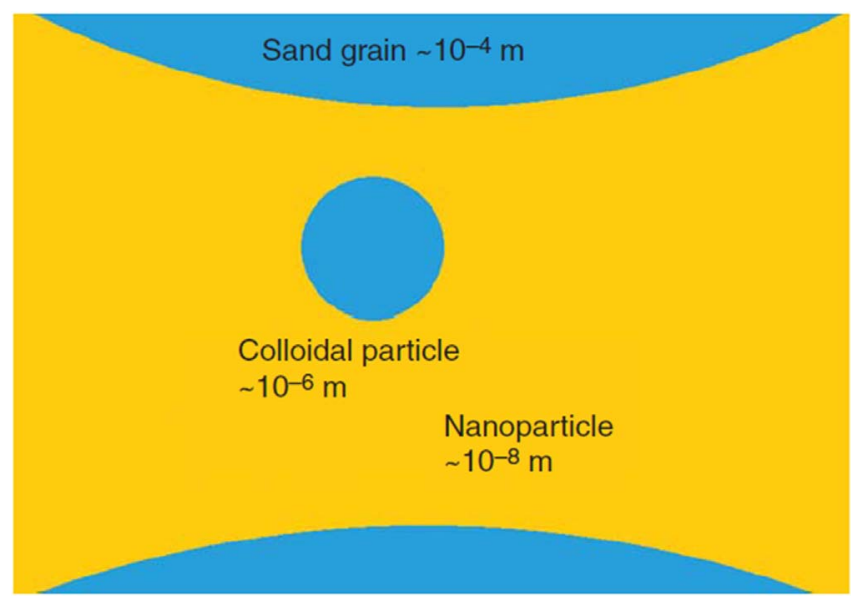

Fig. 1. Scale scan of sizes of nanoparticle, colloid particle, and sand grains (Zhang et al., 2013).

the nanoparticles from the surface, a post-flush procedure was performed. The authors noted that the rate of adsorption increases with concentration and low rate, but reduces with clay content. Furthermore, the irreversible adsorption sites are independent of the reversible sites and lead to first-order dependence on lithology, brine salinity, and size and coatings of nanoparticles. It is noteworthy that the velocity above which the weak bonding of the nanoparticle to the surface can be broken is referred to the critical velocity.

In a similar study, Yu et al. (2012) investigated the adsorption and transport of silica nanoparticles in sandstone, limestone, and dolomite formation using both static and dynamic adsorption measurements. Static and dynamic tests both showed a low adsorption of nanoparticles on sandstone, attributed to its clay content. In contrast, a higher adsorption density is observed in limestone and this is due to the electrostatic interaction between the nanoparticle and the limestone surface. Dolomite, however, showed $0 \%$ adsorption as compared to the other rock sample with permeability and pressure drop increase due to pore plugging. The nanoparticles even though adsorbed on the sandstone and limestone did not record any permeability reduction. These findings present a new argument as to whether the transport of Nanoparticle posses' threat of surface retention. In view of this, it is important to note that the main contribution to nanoparticle retention in porous media is due to physicochemical interactions and clearly, a strong repulsion only exists between nanoparticle and sand surface with low salinity in brine.

White (2012) established the dependency of adsorption on the granular size of a porous media (single granule of silica gel) using a thermogravimetric and computational fluid dynamics approach. The silica balls in Figure 2 . $(3.5 \mathrm{~mm}$ and $5.0 \mathrm{~mm}$ ) were utilized as porous media and a conclusion that the degree of surface adsorption increases with the surface area was established. Although the findings provided insight to surface adsorption, only a single granule was used in this case which does not account for 


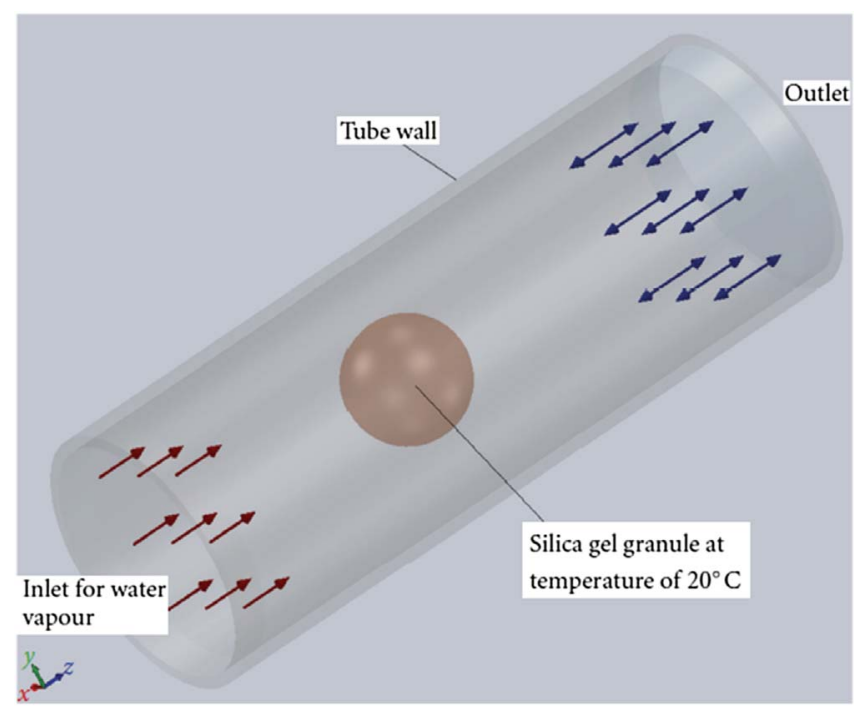

Fig. 2. Single silica gel in a tube geometry used for the validation of CFD and experimental work (White, 2012).

interactions between multiple granules and fluid selectivity on the surface area available.

In modeling Nanoparticle adsorption, the pore structure and geometry, the particle size and surface properties need to be accounted for. One of the most used models is that of Guzman et al. (2006) who described the electrostatic double-layer interaction energy for nanoparticle adsorption based on van der Waals interaction. Guzman model (Eq. (1)) accounts for the pitfalls of the empirical correlations which rather well predict pressure loss for flows but provide nothing more about local flow fields of our adsorption/desorption on porous media:

$$
\text { see equation (1) bottom of the page }
$$

where,

$$
k^{-1}=\left(\frac{\varepsilon_{0} \varepsilon_{r} k_{\mathrm{B}} T}{2 e^{2} I_{c} N_{\mathrm{A}}}\right)
$$

$\varepsilon_{0}$ is the vacuum permittivity, $\varepsilon_{r}$ the relative dielectric constant of water, $k$ is inverse of Debye length, $e$ are elementary charges, $I_{c}$ is suspension ionic strength, $\phi_{\text {EDL }}$ is electric double layer interaction energy, $a$ is the radius of a sphere, $r$ is any distance radius, $D$ is the distance of closest approach between the two surfaces, $k_{\mathrm{B}}$ is Boltzmann, $T$ is temperature, constant, $N_{\mathrm{A}}$ Avogadro number, $\Psi_{\mathrm{s}}$ and $\Psi_{\mathrm{p}}$ are particle and surface potentials.

Nanoparticles are generally small that they easily move within the pores of rock materials without plugging it, but sometimes due to affinity for one another, the nanoparticles are retained on the rock surface. On the bases of Derjaguin, Landau, Verwey, and Overbeek (DLVO) theory, Abdelfatah et al. (2017) came up with theoretical equations that calculated the deposition and release rate under different ionic strengths, $\mathrm{pH}$ and temperature conditions. The authors developed a model to determine Zeta potential of rock and nanoparticles at different conditions and validated it with an experiment that determines the rate at which silica nanoparticles are deposited and released on sandstone formation. It has been observed that an increase in ionic strength and temperature leads to a decrease in the energy barrier height (zeta potential). Consequently, the rate of deposition increases, whereas a change in $\mathrm{pH}$ depends on the isoelectric point of the nanoparticle and pore surface. There is a direct correlation between the two properties, at a higher $\mathrm{pH}$ and zeta potential value, the rate of deposition of matter decreases. The rate of dispersion of nanoparticles on the rock is governed by the zeta potential in addition to the electrostatic interaction. In the same vein, surface potential depends on $\mathrm{pH}$, see equation (3):

$\psi_{s}=\frac{\beta}{\beta+1} \frac{2.3 k_{\mathrm{B}} T}{e}\left(\mathrm{pH}_{\mathrm{IEP}}-\mathrm{pH}\right)=m_{1} \frac{2.3 k_{\mathrm{B}} T}{e}\left(\mathrm{pH}_{\mathrm{IEP}}-\mathrm{pH}\right)$,

where $\psi_{\mathrm{s}}$ is the surface potential, $\mathrm{pH}_{\text {IEB }}$ is the isoelectric point of the surface, $e$ is elementary charge, $m_{1}$ is the slope of the fast region of zeta potential calculation, $\beta$ is surface sensitivity property. Ohshima (1994) came up with a simple approximation that determines Henry's function, $f\left(k \alpha_{p}\right)$, which determines the ionic strength usually in the range of $1-1.5$ :

$$
\begin{aligned}
f\left(k \alpha_{p}\right) & =1+0.5\left[1+\frac{2.5}{k \alpha_{p}\left(1+e^{-k \alpha_{p}}\right)}\right]^{-1}, \\
k^{-1} & =\sqrt{\frac{\epsilon k_{\mathrm{B}} T}{2000 e^{2} N_{\mathrm{A}} I}},
\end{aligned}
$$

where $f\left(k \alpha_{p}\right)$ is Henry's function, $k^{1}$ is Debye length, $\alpha_{p}$ the radius of the nanoparticle, $I$ ionic strength, $N_{\mathrm{A}}$ is Avogadro number, $e$ is elementary charge, $\in$ is dielectric constant, $k_{\mathrm{B}}$ is Boltzmann constant, and $T$ temperature in Kelvin. Revil et al. (1999) came up with a relationship for silica nanoparticle's zeta potential $(\zeta)$ and temperature and is given by,

$$
\zeta(T)=\zeta\left(T_{0}\right) \times\left[1+v_{\zeta}\left(T-T_{0}\right)\right],
$$

$$
\phi_{\mathrm{EDL}}=\pi \epsilon_{0} \in_{r}\left(\Psi_{s}^{2}+\Psi_{p}^{2}\right) \int_{0}^{a}\left(\begin{array}{l}
-\operatorname{coth}\left[k\left(D+a-a \sqrt{1-(r / a)^{2}}\right)\right]+\operatorname{coth}\left[k\left(D+a+a \sqrt{1-(r / a)^{2}}\right)\right] \\
+\frac{\left(2 \Psi_{s} \Psi_{p}\right)}{\left(\Psi_{s}^{2}+\Psi_{p}^{2}\right)}\left\{\operatorname{csch}\left[k\left(D+a-a \sqrt{1-(r / a)^{2}}\right)\right]-\operatorname{csch}\left[k\left(D+a+a \sqrt{1-(r / a)^{2}}\right)\right]\right\}
\end{array}\right) r \mathrm{~d} r,
$$


where symbol $v_{\zeta}$ as temperature sensitivity coefficient, it is an experimented property for different particles, $T_{0}$ room temperature. Ding et al. (2015) express the zeta potential when $x \_s \approx k^{1}$ in equation $(7)$ :

$$
\zeta=\psi_{s} \exp \left(-k x_{s}\right)=\psi_{s} \exp (-1),
$$

combining the equations that describes its' relationship with temperature, ionic strength and $\mathrm{pH}$, an expression for zeta potential can be derived in equation (8),

$$
\zeta=m_{1} \frac{0.85 k_{B} T}{f\left(k \alpha_{p}\right) e}\left(\mathrm{pH}_{\mathrm{IEP}}-\mathrm{pH}\right)\left[1+v_{\zeta}\left(T-T_{0}\right)\right],
$$

for a fast change region, and in equation (9),

$$
\zeta=\zeta_{\text {cut-off }}+\frac{m_{2}}{f\left(k \alpha_{p}\right)}\left(\mathrm{pH}_{\text {cut-off }}-\mathrm{pH}\right)\left[1+v_{\zeta}\left(T-T_{0}\right)\right],
$$

for a slow change region, where $m_{2}$ is the slope of a slow region of zeta potential calculation, $\mathrm{pH}_{\text {cut-off }}$ is fitted cut-off point, other definitions of terms are as stated earlier.

Zhang (2012) integrated the effects of energy barrier and pore surface area in the modeling of the nanoparticle build-up and liberation speed, with the convectiondiffusion equation. The reaction is first-order and the rate of deposition varies as a function of time, described in equation (10):

$$
K_{\text {dep }}(t)=K_{\text {dep }}\left(t_{0}\right) \times B(\theta),
$$

where $B(\theta)$ is the fraction of surface covered already using monolayer coverage. $K_{\mathrm{dep}}$ and $K_{\text {rel }}$ are generally expressed in equations (11) and (12) respectively:

$$
\begin{gathered}
K_{\text {dep }}=D\left(y_{\max }\right) \times\left(\frac{\gamma_{\max }}{2 \pi k_{\mathrm{B}} T}\right)^{\frac{1}{2}} \times \exp \left(\frac{-\left|\phi_{\max }\right|}{k_{\mathrm{B}} T}\right), \\
K_{\text {rel }}=D\left(y_{\max }\right) \times \frac{\left(\gamma_{\max } \gamma_{\min }\right)^{\frac{1}{2}}}{2 \pi k_{\mathrm{B}} T} \times \exp \left(\frac{-\left|\phi_{\max }-\phi_{\min }\right|}{k_{\mathrm{B}} T}\right),
\end{gathered}
$$

where $y_{\max }$ is maximum distance of separation between boundaries.

Validating the values of $K_{\text {dep }}$ and $K_{\text {rel }}$ of the nanoparticles on the rock surface, a numerical simulator was created to compare experimental data from literature with the model results at the same conditions. The model was generated based on certain conditions, such as,

(a) assuming one-dimensional advection-dispersion process

(b) one sink/source term

(c) piston like displacement

(d) with $C(x, 0)=0, C(0, t)=C_{\mathrm{inj}}, \frac{\partial C(L, t)}{\partial x}=0$ as the boundary conditions.

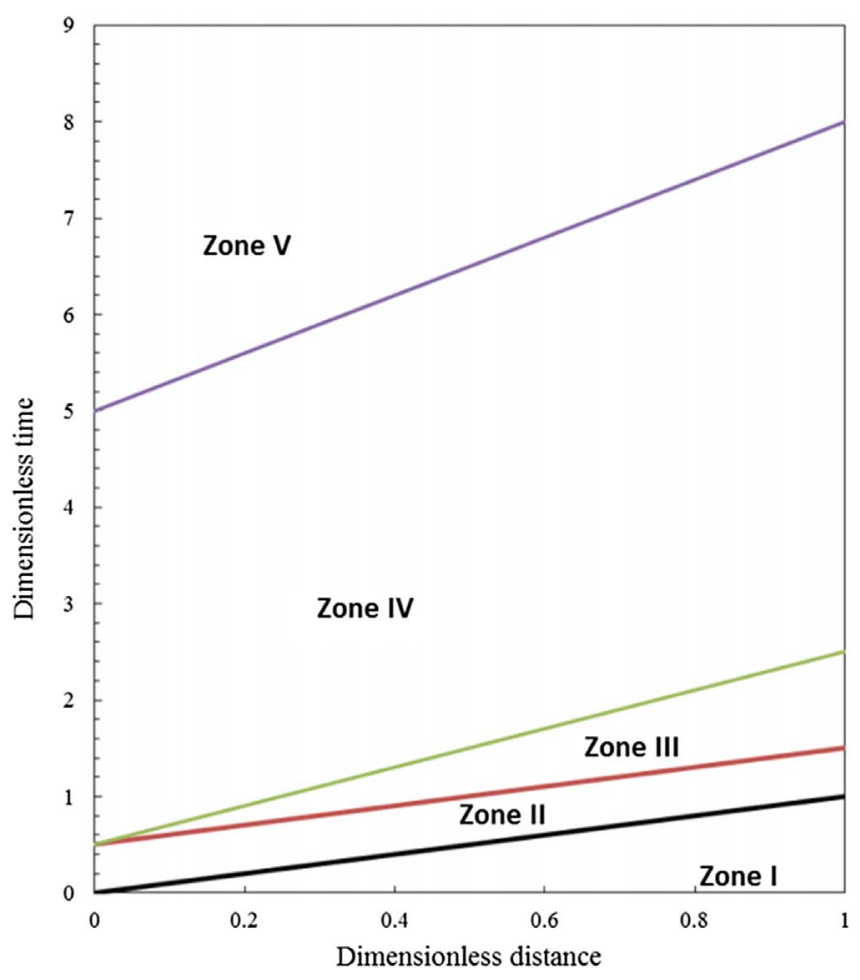

Fig. 3. A distance-time diagram showing the division of zones (Wang et al., 2016a).

Using the Forward Time-Central Space (FTCS) method, Zhang (2012) presented equation (13) to solve the depositional problem in the simulator earlier described:

$$
\text { see equation (13) bottom of the page }
$$

where $i=2,3, \ldots N-1$.

The physical properties of materials and nature of the rock affect the rate at which silica nanoparticles are deposited on the sandstone surfaces. The main conditions that determine the rate of deposition are, (1) larger the size of the nanoparticles greater is the rate of deposition, (2) high temperature, and $\mathrm{pH}$ decreases the rate of deposition, (3) lower the ionic strengthen lower the rate of deposition.

Wang et al. (2016a) applied the method of characteristics to derive an analytical model for quantifying the nanoparticle adsorption/detachment, straining behavior, and other associated effects of fluid flow.

$\mathrm{Yu}$ et al. (2012) studied the behavior of nanoparticle adsorption and transportation in three different cores namely limestone, Berea sandstone, and dolomite. The results show that convection, diffusion, and hydrodynamics govern the flow of nanoparticles in the medium. In addition, the authors showed that for the three-rock samples, whenever equilibrium is reached, nanoparticles tend to flow freely within the medium without further retention or adsorption.

$$
\frac{c_{i}^{n+1}-c_{i}^{n}}{\Delta t}+\frac{u}{\emptyset} \frac{3 c_{N}^{n}-4 c_{N-1}^{n}+c_{N-2}^{n}}{\Delta x}=D \frac{2 c_{N}^{n}-5 c_{N-1}^{n}+4 c_{N-2}^{n}+c_{N-3}^{n}}{\Delta x}+R^{n}+o\left(\Delta t,(\Delta x)^{2}\right),
$$


An estimated value of around $1.27 \mathrm{mg} / \mathrm{g}$ for every $5000 \mathrm{ppm}$ was obtained to be the adsorption equilibrium. Lastly, a core flooding test reveals that the nanoparticle injected into the core did not alter the original core permeability. Injecting nanofluid (fluid-carrying nanoparticles) into a porous media leads to either of the following; adsorption, desorption, blockage, aggregation, and transport of the particles depending on the nature of the particle, the porous media, etc. There is an interesting phenomenon called Aggregation, that is a common attribute with most nanoparticles. These very tiny particles tend to bind to one another, and this mechanism results in size increase from Nano to a micro-scale (Idris and Kadafur, 2015).

$\mathrm{Li}$ et al. (2018) conducted a study using silicon dioxide as a nanoparticle to see its effect on the contact angle. The authors found out that, the nanoparticles reduce the contact angle existing between oil and water, and as such, it has the potential of changing the rock surface to more water-wet irrespective of its initial wettability. In the research, Li et al. carried out microfluidic flooding on glass grains, which shows that nanofluid flooding can alter the wettability of glass grain from an oil-wet system to water wet due to the adsorption of the nanoparticles on the glass grains. Similarly, the authors conducted a research to study the impact of nanoparticle adsorption on wettability alteration by using a natural core. Thus, coreflood experiments were conducted on a Berea sandstone plug. Results indicated that the wettability of sandstones altered to slightly more water-wet and the contact angle between oil and brine on the glass surface was reduced by $10^{\circ}$ when hydrophilic nanoparticles were used. On the contrary, the use of hydrophobic nanoparticles did not bring any noticeable difference in the wettability of core plugs, however spontaneous imbibition was delayed. The authors also noted that there was significant nanoparticle retention and permeability impairment when using hydrophilic Fumed Nanoparticles (FNP) whereas hydrophilic silica Colloidal Nanoparticles (CNP) had no influence on the permeability (Li et al., 2019).

Li and Torsæter (2015) used an hydrophilic silica NanoStructure Particle (NSP-W), hydrophilic silica Colloidal Nanoparticle (CNP), and hydrophobic silica Nanostructure particles (NSP-O) alongside brine and n-decane as solvents for the nanoparticles, and studied the impact of the nanoparticles adsorption and transportation. The experiment was conducted using an n-decane oil of density 0.73, on 20 short core plugs and 6 long cores of Berea sandstone with average permeability of $316 \mathrm{mD}$ and an average porosity of $18.3 \%$ using an Amott cell and a centrifuge to determine the wettability index. In determining the number of nanoparticles transported, the concentration of the injected nanofluid recovered at the effluent was measured using a UV spectrophotometer while the wettability was determined after carrying out a series spontaneous/forced imbibition and drainage process using the wettability index formula in equation (14):

$$
\mathrm{WI}=\frac{V_{o 1}}{V_{o 1}+V_{o 2}}+\frac{V_{w 1}}{V_{w 1}+V_{w 2}}
$$

where $V_{\mathrm{o} 1}$ and $V_{\mathrm{w} 1}$ are volume of fluid produced during spontaneous imbibition, whereas $V_{\mathrm{o} 2}$ an $V_{\mathrm{w} 2}$ is the fluid produced during forced imbibition.

The experiment reveals that both hydrophilic NSP and CNP have the potential to increase the wettability of the core making it more water wet, whereas using the hydrophobic (NSP-O) shows no alteration to the original core wettability. On the nanofluid transportation, the experiment shows that both (NSP-W and CNP) nanoparticles behave in a different manner within the core. The result also shows that NSP-W's adsorption in the core is multilayered whereas CNP is monolayer; this means that NSP-W is more adsorbed, and this results in decreasing the permeability. A post flush injection was carried out to see the rate of their desorption, the result shows that little to no amount of NSP-W was desorbed but a greater amount of CNP was recovered.

Arain et al. (2019) studied the reversible and irreversible adsorption of silica nanoparticles on carbonate surfaces at reservoir conditions. They used Iceland spar has a representative of carbonate reservoirs. Dynamic Light Scattering (DLS), Scanning Electron Microscope (SEM), EnergyDispersive X-ray Spectroscopy (EDS), and Atomic Force Microscopy (AFM) measurements were used to obtain an understanding of the adsorption of nanoparticles on the carbonate surface. Results showed that only a limited amount of hybrid (salinized) silica nanoparticles were adsorbed by the calcite surface at reservoir conditions. Results also indicated that the hybrid NPs showed limited aggregation in the liquid phase however the Bare silica resulted in large aggregates. The bare NP clusters were reversibly adsorbed on the surface (Arain et al., 2019).

The nanoparticle transport in porous media can be defined by equation (15) (Ju et al., 2012; Ju and Fan, 2009; Sepehri et al., 2019)

$$
u_{l} \frac{\partial C_{i, l}}{\partial x}+\phi S_{l} \frac{\partial C_{i, l}}{\partial t}-\frac{\partial}{\partial x}\left(\phi S_{l} D_{i, l} \frac{\partial C_{i, l}}{\partial x}\right)+R_{i, l}=0,
$$

where, $C_{i, l}$ is the volume concentration of nanoparticles in the interval $i$ in phase $l, D_{i, l}$ is the dispersion coefficient, $S_{l}$ is the saturation of phase $l, \phi$ is the porosity of the medium, and $R_{i, l}$ is the rate of loss of nanoparticles.

The loss of nanoparticles can be due to two main reasons: adsorption on the surface of pores, and blockage in pore throats (Ju et al., 2012). The net rate of loss of nanoparticles, therefore, can be given by equation (16):

$$
\begin{gathered}
R_{i, l}=\frac{\partial v_{i, l}}{\partial t}+\frac{\partial v_{i, l}^{*}}{\partial t}, \\
\frac{\partial v_{i, l}}{\partial t}= \begin{cases}\alpha_{d, i, l} u_{l} C_{i, l} ; & u_{l}<u_{l c} \\
\alpha_{d, i, l} u_{l} C_{i, l}-\alpha_{e, i, l} v_{i, l}\left(u_{l}-u_{c}\right) ; & u_{l}>u_{l c}\end{cases}
\end{gathered}
$$

The equation for entrapment of particles in pore throats is given by equation (18)

$$
\frac{\partial v_{i, l}^{*}}{\partial t}=\alpha_{p t, i, l} u_{l} C_{i, l}
$$


Table 1. Summary of the analytical solution obtained for suspended, attached, and strained nanoparticle concentration (Wang et al., 2016a).

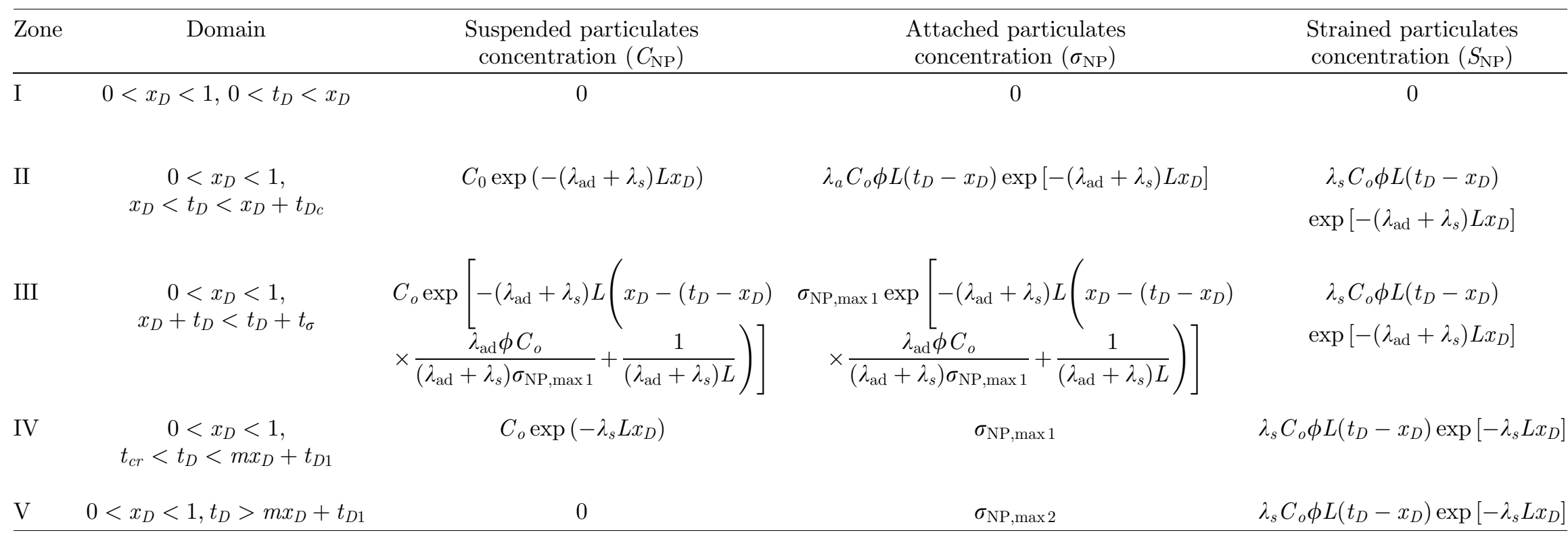

Here, $x_{D}$ is the dimensionless distance, $t_{D}$ is the dimensionless time, $t_{\mathrm{Dc}}$ is the dimensionless time or injected pore volume at maximum nanoparticles concentration, $t_{D 1}$ is the dimensionless time or injected pore volume start post-flush without nanoparticles, $C_{o}$ is the volumetric concentration of injected nanoparticles, $\lambda_{s}$ is the straining filtration coefficient, $\lambda_{\text {ad }}$ is the adsorption filtration coefficient, $\phi$ is the porosity of sand pack, $L$ is the length of the sand pack, $\sigma_{\mathrm{NP}, \max 1}$ is the maximum retention concentration of nanoparticles with maximum nanoparticle adsorption, $\sigma_{\mathrm{NP}, \max 2}$ is the maximum retention concentration of nanoparticles at the phase of post-flush. Figure 3 shows the division of the different zones on the distance-time diagram. 
where, $v_{i, l}$ is the volume of nanoparticles of interval $i$ in phase $l$ adsorbed on pore surfaces per unit bulk volume of carbonate rock. The rate of adsorption on the surface depends on the critical velocity. Above the critical velocity, only particle retention can occur below this both retention and entrainment can occur (Gruesbeck and Collins, 1982) according to equation (17).

Conclusively, the summary of models for suspended attached and strained nanoparticles is provided in Table 1.

\section{Polymer particle adsorption}

Polymer solutions have become popular in the oil industry owing to the advantage of mobility control they possess. Several fields have implemented this with remarkable success. However, the implementation comes with the challenge of polymer retention on the rock surfaces which impairs the permeability of the formation. The damage on pore throat could be due to poor design of the polymer or inability to consider the effect of reservoir mineralogy on the interaction between fluid and rock surface. Despite the flow assurance issues caused due to polymer adsorption on rock surfaces, it has been proved to be advantageous in controlling water production in high water producing wells (Ogunberu and Asghari, 2005). This was reported in a study of polymer retention to modify the water relative permeability from a porous media.

The adsorption of polymer onto a porous media has been established to be due to polymer concentration, rock mineralogy, reservoir temperature, pore structure, and polymer particle sizes, etc. This factor contributes to the adsorption mechanisms of polymer which are adhesion to rock surface, trapping and particle entrainment (Dang et al., 2014; Khormali et al., 2018; Landes, 1961; Liu et al., 2006; Mungan, 1969; Ogunberu and Asghari, 2005).

Cheraghian et al. (2014) reported the adsorption of polymers on reservoir rocks using Nanoparticles of clay and $\mathrm{SiO}_{2}$. The findings depicted a lower adsorption of polymers on the surface and a higher adsorption on carbonate rock as compared to sandstone. This disparity in the two rocks is attributed to the different porosities, mineralogy, and cracks. Polymer adsorption has been most modeled by Langmuir adsorption isotherm with relatively good agreement. Khormali et al. (2018) used the Langmuir and Freundlich isotherm models for polymer adsorption modeling on carbonate and sandstone reservoir rocks. Dang et al. (2014) highlighted the effect of polymer concentration, molecular weight, $\mathrm{pH}$, salinity and reservoir heterogeneity on adsorption. They noted that at low concentration, adsorption is proportional to the polymer concentration however at high concentration the rate of adsorption decreases and possesses a different threat of pore plugging due to mechanical entrapment. An increase in $\mathrm{pH}$ results in a decrease in adsorption due to a repulsive effect between the polymer and the rock surfaces. On the other hand, an increase is observed in the case of increasing salinity.

Hematfar et al. (2013) reported the effect of high salinity water film in asphaltene adsorption in porous media. As the salt content increases, the water film gains more strength that prevents asphaltene particle penetration. Consequently, there is reduction in asphaltene adsorption to a porous media. It is noteworthy that this observation is independent of asphaltene concentration. Mungan (1969) also reported the effect of temperature on the rate of polymer adsorption. The author noted that, though high temperatures may lead to polymer degradation, it can help reduce the surface adsorption. For this reason, the optimal selection of polymer is critical to successful implementations.

Darcy equation models the Newtonian behavior of polymers in the porous media at a low flow rate. However, it fails to represent the pseudo-plastic and dilatant nature at intermediate and high flow rate conditions respectively (Abraham, 1966; Burcik, 1965; Dauben and Menzie, 1967; Gogarty, 1967; Jennings et al., 1971; Rowland and Eirich, 1966; Savins, 1969; Smith, 1970). Blake-Kozeny equation models have increasingly become popular in describing the pseudo-plastic behavior of polymers, using bundles of capillary tubes in viscometric measurements, nevertheless, the rheological model neglects the effect of tortuosity in pore geometry.

Nonetheless, Christopher and Middleman, (1965) modified the Blake-Kozeny model by introducing a constant tortuosity factor of 25/12 to depict the effect of pore geometry in the flow of the power-law fluid. The authors validated the equation by applying it to estimate the apparent viscosity of the Kelzan-M biopolymer solution through cores with a residual oil saturation. Though the result only deviated from the laboratory values by less than $10 \%$, unfortunately, it will behave poorly when adopted to high flow rate polymers because it did not consider the relaxation time, which sets in due to the deformation of the fluid.

Interestingly, Marshall and Metzner (1967) introduced a qualitative measure to describe a visco-elastic behavior of polymers using Deborah number. The authors related the dimensionless number to the relaxation time of the polymer, polymer shear rate, polymer elastic modulus, and the rock porosity and permeability. Not only does the deformation effect on the rheologic fluid greater for lower permeability system if the fluid is flowing at the same velocity, but the relaxation time is also higher for larger molecular weight polymers (Abraham, 1966; Dauben and Menzie, 1967; Jennings et al., 1971; Smith, 1970). Sadly, the limiting factor is that the authors did not consider the elongation rate (shear-thickening and thinning rate) on the qualitative index used. In addition, with partially hydrolyzed acrylamide, the permeability reduction due to polymer adsorption is significant and must be accounted for. Meanwhile, earlier authors attributed all flow resistance in porous media non-Newtonian fluid flow to adsorption (Christopher and Middleman, 1965; Hirasaki and Pope, 1974; Marshall and Metzner, 1967; Metzner, 1977; Savins, 1969) but some others believed that no correlation exists to distinguish the two types of polymer retention which are adsorption and mechanical entrapment or plugging (Jennings et al., 1971; Smith, 1970). 


$$
\frac{\partial}{\partial t}\left(\phi \rho_{w} S_{w} C^{w}+(1-\phi) \rho_{r} C^{r}\right)+\nabla \cdot\left(\frac{\rho_{w} C^{w}}{\left(1-\alpha_{P}\right) R_{m}} u_{w}\right)+\rho_{w} q_{w} C^{w}=0
$$

Polymer transport in a dead oil model can be modeled using the following equation (Braconnier et al., 2017):

$$
\text { see equation (19) top of the page }
$$

where, $\rho_{w}$ is the density of water, $S_{w}$ is the saturation of water phase, $C^{w}$ is polymer mass fraction, $C^{r}$ is the mass fraction of polymer adsorbed on the surface of the rock, $\rho_{r}$ is the density of the rock and $\rho_{w}$ is the density of water, $\alpha_{P}$ is the inaccessible pore volume, $q_{w}$ is the source term per unit volume, and $\boldsymbol{u}_{\mathrm{w}}$ is a vector of water velocity.

The Inaccessible Pore Volume (IPV) is the volume of the pore than cannot be reached by the polymer. This phenomenon occurs when the size of the polymer molecules becomes larger than some pores in the porous media. It is an important phenomenon and needs to be considered to design an effective EOR technique (Dawson and Lantz, 1972; Dominguez and Willhite, 1977; Sheng, 2011; Sorbie, 1991).

The mass fraction of polymer adsorbed $\left(C^{r}\right)$ can be modeled using different techniques. Some of the major techniques are listed as follows (Braconnier et al., 2017).

Instantaneous adsorption: The adsorption is constant as soon as the minimum polymer mass fraction is attained. This method is not reversible and not a good choice for modeling:

$$
C^{r}=\left\{\begin{array}{l}
q_{p}^{\max } ; \quad \phi \rho_{w} S_{w} C^{w}+(1-\phi) \rho_{r} C^{r} \geq(1-\phi) \rho_{r} q_{p}^{\max } \\
o
\end{array},\right.
$$

where $q_{p}^{\max }$ is the maximum adsorption capacity of the rock.

Schematic adsorption: Composed of two regimes, grows linearly until a rock adsorption limit is achieved after which there is no more polymer adsorption. This is also irreversible

$$
C^{r}=q_{p}^{\max } \min \left(1, \frac{C^{w}}{C^{*}}\right),
$$

where $C^{*}$ is the reference mass fraction determining the adsorption dynamic. Langmuir Isotherm: It is the most useful for mathematical modeling and is reversible. It is given by

$$
C^{r}=q_{p}^{\max } \frac{b C^{w}}{1+b C^{w}}
$$

where $b$ is the Langmuir coefficient.

\section{Factors affecting polymer adsorption}

Rowland and Eirich (1966) conducted an experiment with polyacrylamide type polymers of different molecular weight, accompanied solvent (brine) of a wide range of salinity and a variety of cores. This led to the introduction of two qualitative indices to determine the adsorption thickness on the matrix surface; referred to as the dimensionless pore-radius reduction number, $N_{\delta}$, and the permeability
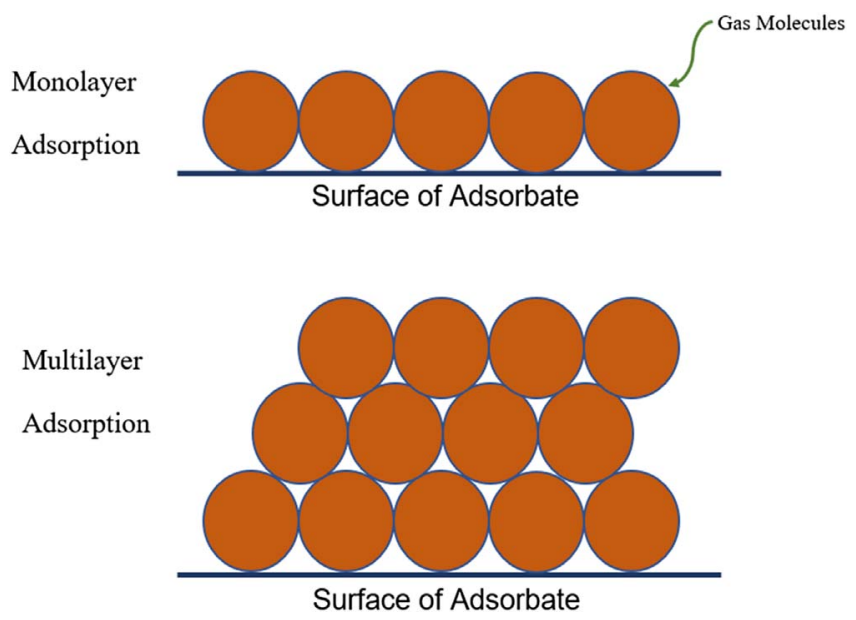

Fig. 4. Monolayer vs. Multilayer Adsorption.

reduction factor $R_{k}=R_{f} \mu_{\mathrm{w}} / \mu_{\mathrm{app}}$. The authors represented these dimensionless parameters to be dependent on the properties of the polymers, accompanied solvent, and the rock. Similarly, in order to generally account for other factors such as pore plugging, error in laboratory measurements, clay content, pore size distribution, and rock mineralogy that may cause permeability reduction; the authors benchmark a plot of the two dimensionless property with an idealized permeability reduction factor equation, $R_{k}=$ $\left(1-\beta N_{\delta}\right)^{-4}$ and obtained a fitting parameter, $\beta$. If the beta parameter is between zero and one, to show the degree of deviation from one:

$$
N_{\delta}=\frac{3.9 \times 10^{-3} M^{\frac{1}{3}}[\mu]^{\frac{1}{3}}}{\left(\frac{k}{\phi}\right)^{\frac{1}{2}}},
$$

where, $M$ is the polymer molecular weight, $\mathrm{g} / \mathrm{mol} ; k$ is the absolute permeability, $\mu_{\text {app }}$ is obtained from the BlakeKozeny power-law model; $R_{f}$ is the resistant factor; $\mu_{\mathrm{w}}$ is the viscosity of the accompanied brine, and $[\mu]$ is the intrinsic viscosity of the polymer.

Furthermore, the author presented a quantitative measure of the monolayer-adsorbed polymer thickness, in equation (24) as a function of polymer molecular weight, the segmented density of the ionized group of the polymer, the solvent (brine) $\mathrm{pH}$ and salinity, specific pore surface area of matrix, internal viscosity of the polymer, and the rock porosity and permeability values and a constant tortuosity parameter 5/12:

$$
r_{\mathrm{ad}}=118 \frac{\phi^{3 / 2}}{\sqrt{k}} \frac{M^{1 / 3}}{[\mu]^{2 / 3}} \frac{\sigma_{\mathrm{sgd}}}{\rho_{\mathrm{b}}},
$$

where, $\sigma_{\mathrm{sgd}}$ is the segmented density of the ionizable group in the polymer, which depends on the affinity of the mineral surface for the polymer molecules; $\rho_{\mathrm{b}}$ is the bulk 


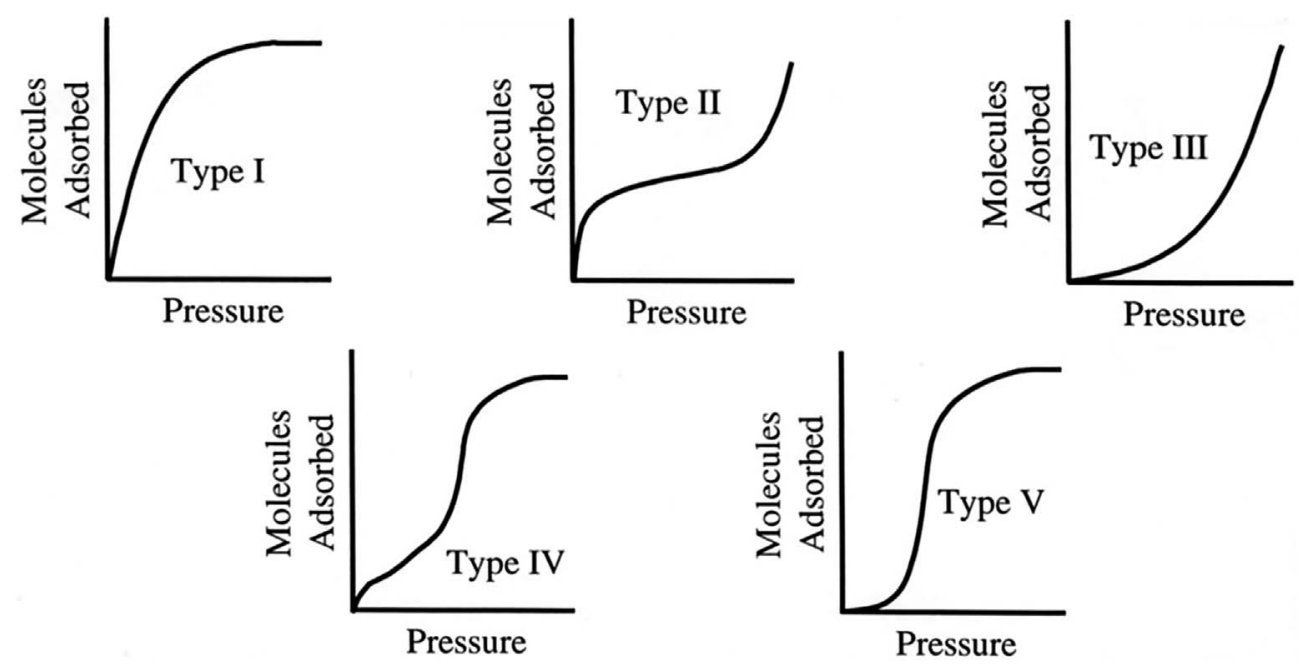

Fig. 5. The five types of adsorption isotherms (Agarwal, 2012; Brunauer et al., 1940).

density of the rock, $\phi$ is porosity, $M$ polymer molecular weight, and $k$ is absolute permeability.

The authors pointed out that the salinity of the accompanying brine can have a significant influence on the theoretical polymer adsorption thickness; for instance, the reduction in solvent salinity from $5000 \mathrm{ppm}$ to zero can increase the intrinsic viscosity of the polymer by a factor of 100 . Most important to note is that some of these parameters such as solvent $\mathrm{pH}$ and polymer concentration have a critical point beyond which the effects on polymer adsorption will be little, for polymer concentration it is beyond $0.05 \%$ wt. Similarly, for $10 \% \mathrm{NaCl}$ solvent, adsorption of partially hydrolyzed polyacrylamide in carbonate rock is six times more than in silicate rock. However, the presented models will not be applicable for high flow rate polymers and cannot differentiate the contribution of residual oil saturation, pore plugging, pore size distribution and clay effects from adsorbed polymer thickness, thus referred to as a theoretical value (Gogarty, 1967; Willhite and Dominguez, 1977).

Experimental techniques have been developed to distinguish adsorptive from non-adsorptive polymer bed. Silane treatment is applied to one of the packed silica sand-bed samples, to change the functional group of the readily adsorbed silica surface to methyl group, thereby rendering the rock non-adsorptive to the developed Hydrolyzed Polyacrylamide (HPAM) (Cohen and Christ, 1986; Dominguez and Willhite, 1977; Szabo, 1975). Further, the ratio of the exit $C$, to the entry HPAM concentration $C_{o}$, was recorded. Thereafter, the authors plotted the ratio against pore volume injected. If there is no retention, $C / C_{\mathrm{o}}=1$, which means that the concentration remains unchanged. Most importantly, the area between the adsorbing and non-adsorbing samples represents the adsorptive retention part of the total retention, while, $\left(C / C_{\mathrm{o}}>1\right)$ indicates that desorption took place. The authors compared the total concentration before and after for the two cases, and the results showed that while,
$32.6 \mu \mathrm{g}$ and $21 \mu \mathrm{g}$ of polymer per $1 \mathrm{~g}$ of adsorbent was retained in the adsorbed bed; $15.7 \mu \mathrm{g}$ and $10 \mu \mathrm{g}$ of polymer per $1 \mathrm{~g}$ of adsorbent was retained in the non-adsorbed bed as reported by Cohen and Christ, and Dominguez and Willhite, respectively. Generally, this accounted for only $35.2 \%$ adsorbed polymer of the total retained and Effective Hydrodynamic Thickness (EHT) of the adsorbed polymer layer is $0.57 \mu \mathrm{m}$ obtained at the lowest stress level of $0.375 \mathrm{~Pa}$. The authors observed that as the shear stress level increases, the mobility reduction effect of the polymer reduces and consequently the EHT drops. An equation for approximating the theoretical adsorbed polymer thickness for low-velocity flow conditions was introduced and given as

$$
r_{\mathrm{ad}}=\frac{\phi d}{3(1-\phi)}\left(1-\frac{k_{\mathrm{ads}} \mu_{\mathrm{app}}}{k \mu_{\mathrm{app}, \mathrm{ads}}}\right)^{\frac{n}{3 n+1}},
$$

where $\mu_{\text {app }}$ and $\mu_{\text {app,ads }}$ are the apparent viscosity measured in the non-absorbed and adsorbed silica sand respectively; $n$ and $K$ are the fitting parameters of the power-law model for the polymer $\sigma_{\text {shear }}=K \dot{\gamma}^{n}$ and $\dot{\gamma}$ is the shear rate. However, for the adsorbed silica, the author did not account for the effect of the electrophilic head of the different types of polymer and their molecular weight on the EHT approximation model.

\section{Gas adsorption}

Over $20-80 \%$ of shale gases are stored in adsorbed phase under conditions that are affected by several factors such as the total organic content, temperature, specific volume ratio, mineralogy, etc. leading to phase interactions (Bustin et al. 2008; Curtis et al. 2010; Huan-Zhi and Yan-qing, 2010; $\mathrm{Lu}$ et al., 1995). Gas molecular interactions with rock surfaces result in gas adsorption onto the surface with the 
effect being an increase in the density of the gas molecules at fluid/solid interface and a reduction in the gas phase density. The adsorption process can be physical or physisorption which is controlled by van der Waals forces or chemisorption which is governed by covalent bonding. The reversibility of this process as well as the adsorption capacities is controlled by several factors such as temperature, nature of surfaces, pressure, amount and nature of gas molecules and rock heterogeneity (Tan et al., 2014; Xiao-Chun et al., 1995; Zhang et al., 2012). Critical to the understanding of such systems is the knowledge of gas adsorption capacity, which is a key to reserve estimation in shale formation and the dynamics of production. The adsorption capacity measurement entails measuring the volume of gas adsorbed on the rock surface at constant temperature, pressure or amount of gas. Adsorption isotherms, isobars and isosteres are then generated to determine the relationship between temperature, pressure or amount of gas at equilibrium (Bertier et al., 2016). Various models have been developed to predict the adsorption capacity based on different adsorption mechanisms, the major classifications being: (1) Monolayered and multilayered models, (2) single component and multicomponent models.

\subsection{Monolayered vs. multilayered models}

In monolayered adsorption the adsorbed molecules occupy only certain adsorption sites and are in direct contact with the surface layer of the adsorbent, whereas under multilayered adsorption the molecules of gas phase can be adsorbed in more than one layer and therefore all the molecules are not in direct contact with the surface layer of the adsorbent. The sketch presented in Figure 4 differentiates between the two forms of adsorption.

After conducting extensive literature review Brunauer et al. (1940) put forward five isotherm shapes (Fig. 5) which could incorporate all adsorption isotherm models (Brunauer, 1943; Brunauer et al., 1940). Type I isotherms are encountered when the adsorption is limited to a single layer and are generally encountered during chemisorption on microporous powders (pore diameter $<2 \mathrm{~nm}$ ). At high pressure the pores are saturated with the adsorbate and no additional adsorption occurs. In Type II isotherms the amount adsorbed increases with increasing pressure and then reaches a plateau, this happens when monolayer adsorption is completed. On further increasing the pressure multilayer adsorption occurs (Masel, 1996). Type III isotherms are characterized by very little initial adsorption. However, as adsorption proceeds additional adsorption is facilitated because the adsorbate interaction with the adsorbed layer is greater than the interaction with the adsorbent surface (Lowell et al., 1991). Type IV isotherms occur due to capillary condensation where gas condenses in the tiny capillary pores of the solid at pressures less than the saturation pressure of gas. At lower pressures a formation of monolayer is observed followed by formation of multilayers. Type V is similar to Type III in that they show small adsorbate-adsorbant interaction however they occur on similar adsorbants as a Type IV isotherm. The most common monolayer models include Langmuir (Langmuir, 1918; Zhang et al., 2012), Freundlich model (Ahmadi and Shadizadeh, 2015; Freundlich, 1909), Langmuir-Freundlich model (Wang et al., 2016b,c), D-R model (Chen et al., 2017; Rani et al., 2019), and the Toth model (Rexer et al., 2013; and Bae and Bhatia 2006). While the most commonly used multilayer model is the BET model (Brunauer et al., 1938; $\mathrm{Yu}$ et al., 2016). Table 2 lists some of the most commonly used monolayer and multilayer models.

Under this section, we discuss further in detail the Langmuir model, The DR and DA models, and the BET model for gas adsorption. Detailed discussions of all the other isotherms can be found in the exhaustive reviews on adsorption isotherms conducted by Saadi et al. (2015) and Ayawei et al. (2017).

\subsubsection{Langmuir model}

The Langmuir model has generally been the most implemented model for the prediction of gas adsorption in porous media (Fianu et al., 2019a). It is an equilibrium model that captures the relationship between gas pressure and the quantity of gas adsorbed at a constant temperature. The model assumes a homogeneous surface with fixed adsorption sites where monolayer adsorption occurs, with the adsorbed molecules assumed to be non-interacting (Swenson and Stadie, 2019).

The isotherm equation is given by

$$
G_{s}=\frac{V_{\mathrm{L}} P}{P_{\mathrm{L}}+P},
$$

where $G_{s}$ is adsorption capacity, $P$ is pressure, $V_{\mathrm{L}}$ and $P_{\mathrm{L}}$ are Langmuir volume and pressure respectively.

Yan et al. (2016) modeled the flow behavior considering multiple mechanisms such as natural fractures, inorganic matrix, organic matrix (micropores), and organic matrix nanopores. However, the model suitability is limited to single-phase fluid, single-components, and isothermal cases. The Klinkenberg gas slippage term is also neglected. Furthermore, the author provided a numerical simulation solution to the Darcy flow flux and the Fickian diffusion flux given below with no source/sink term:

$$
\frac{\partial C_{\text {free }}}{\partial t}+\frac{\partial C_{\text {sorbed }}}{\partial t}=-\nabla \cdot(\rho \vec{u})
$$

where,

$$
\vec{u}=-\frac{\bar{k}}{\mu}(\nabla P-\rho \vec{g})+D_{g} C_{g} \nabla P,
$$

and, $V$ is the bulk volume of the reservoir, $\mathrm{C}_{\text {free }}=\phi \rho$, is the total mass concentration of free gas phase, $C_{\text {sorbed }}=q_{\mathrm{a}}(1-\phi)$, is the total mass concentration of sorbed phase, $q_{\mathrm{a}}=\rho_{\mathrm{s}} \rho_{\mathrm{g} \text { std }}\left(\frac{P V_{L}}{P_{L}+P}\right), \vec{u}$ is the volumetric flow rate in the reservoir normal to the surface of the rock body, $\rho_{\mathrm{s}}$ is the density of the shale, $V_{\mathrm{L}}$ is the Langmuir volume, $\bar{k}$ is permeability, $\mu$ is viscosity, $P$ is pressure, $\rho g$ is gravity term, $C_{\mathrm{g}}$ is gas compressibility, $D_{\mathrm{g}}$ is gas 
Table 2. Different monolayer and multilayer isotherms.

\begin{tabular}{lcl}
\hline $\begin{array}{l}\text { Monolayer } / \\
\text { multilayer }\end{array}$ & $\begin{array}{c}\text { Number of } \\
\text { parameters }\end{array}$ & \multicolumn{1}{c}{ Adsorption model } \\
\hline $\begin{array}{l}\text { Monolayer } \\
\text { isotherms }\end{array}$ & Two parameters & $\begin{array}{l}\text { Dubinin and Radushkevich (DR), 1947; Flory, 1953; Freundlich, 1909; Langmuir, } \\
\text { 1918; Volmer and Mahnert, 1925; Temkin and Pyzhev, 1940 }\end{array}$ \\
& Three parameters & $\begin{array}{l}\text { de Boer, 1953; Fritz and Schluender (III), 1974; Hill, 1910; Khan et al., 1996; Radke } \\
\text { and Prausnitz, 1972; Redlich and Peterson, 1959; Sips, 1948; Toth, 1971 }\end{array}$ \\
& Four parameters & Astakhov and Dubinin, 1971; Fritz and Schluender (IV), 1974 \\
& Five parameters & Fritz and Schluender (V), 1974 \\
Multilayer & Two parameters & Halsey, 1952 \\
& Three parameters & Aranovich, 1991; BET Model (Brunauer et al., 1938); McMillan and Teller, 1951 \\
& Four parameters & $\begin{array}{l}\text { Anderson (IV), 1946; GAB model (Anderson, 1946; de Boer, 1953; } \\
\text { Guggenheim, 1966); n-layer BET (Yu et al., 2016) }\end{array}$ \\
& Five parameters & Anderson (V), 1946 \\
\hline
\end{tabular}

Table 3. Different adsorption correlations and fitting parameters for Glycyrrhiza Glabra (Ahmadi et al., 2012).

\begin{tabular}{|c|c|c|c|c|}
\hline Isotherm & Correlation & \multicolumn{3}{|c|}{ Parameters } \\
\hline Langmuir & $q_{\mathrm{e}}=\left(q_{\mathrm{o}} K_{\mathrm{ad}} C_{\mathrm{e}}\right) /\left(1+K_{\mathrm{ad}} C_{\mathrm{e}}\right)$ & $\begin{array}{c}R^{2} \\
0.9964\end{array}$ & $\begin{array}{c}q_{\mathrm{o}} \\
51.02\end{array}$ & $\begin{array}{c}K_{a d} \\
0.27\end{array}$ \\
\hline Freundlich & $q_{e}=K_{f} C_{e}^{1 / n}$ & $\begin{array}{c}R^{2} \\
0.9891\end{array}$ & $\begin{array}{c}n \\
0.8412\end{array}$ & $\begin{array}{c}K_{f} \\
9.7946\end{array}$ \\
\hline Temkin & $q_{\mathrm{e}}=B \ln K_{\mathrm{t}}+B \ln C_{\mathrm{e}}$ & $\begin{array}{c}R^{2} \\
0.8733\end{array}$ & $\begin{array}{c}k_{T} \\
5.31\end{array}$ & $\begin{array}{c}B \\
10.599\end{array}$ \\
\hline Linear & $q_{\mathrm{e}}=K_{\mathrm{H}} C_{\mathrm{e}}+c$ & $\begin{array}{c}R^{2} \\
0.9307\end{array}$ & $\begin{array}{c}K_{\mathrm{H}} \\
6.0665\end{array}$ & $\begin{array}{c}C \\
4.8148\end{array}$ \\
\hline
\end{tabular}

Here, $q_{e}$ is the equilibrium adsorption rate, $C_{e}$ is the equilibrium concentration, $q_{o}$ is the adsorption capacity, $K_{\text {ad }}$ is adsorption equilibrium constant, $n$ and $K_{f}$ are Freundlich constants, $B$ is the Temkin constant, $K_{t}$ is the equilibrium binding constant, $K_{H}$ is the constant for linear isotherm, and $c$ is the intercept of the linear isotherm.

diffusivity constant, $P_{\mathrm{L}}$ is the Langmuir pressure and, $q$ is the cumulative flow rate (sink/source).

While the Darcy model describes the flow in natural fractures and the inorganic matrix, some of these models also use the Fickian diffusion flux model to describe the total diffusion flux of the shale rock. Nevertheless, because of hysteresis that occurs in shale, which is a function of ionic interactions and reservoir conditions, the non-equilibrium situation is experienced. In other words, the volume of gas desorption is less than adsorption, similarly total dissolved gas is not commensurate to total micropores and the nanopores diffusion.

An et al. (2017) coupled geo-mechanics and gas flow model to study the effect of stress and matrix shrinkage on gas production performance of organic-rich fractured shale reservoirs. The authors described the governing flow equation for an isothermal single-phase flow system like the equations presented by Yan et al. (2016), they, however, introduced the sink/source term and accounted for Klinkenberg slip factor:

$$
\frac{\partial C_{\text {free }}}{\partial t}+\frac{\partial C_{\text {sorbed }}}{\partial t}=-\nabla \cdot(\rho \vec{u})+\frac{\rho q}{V}
$$

where,

$$
\vec{u}=-\frac{\bar{k}}{\mu}\left(1+\frac{b}{p}\right)(\nabla P-\rho \vec{g})+D_{g} C_{g} \nabla P,
$$

where $\rho_{\mathrm{s}}$ is the density of the shale, $V$ is volume, $\bar{k}$ is permeability, $\mu$ is viscosity, $P$ is pressure, $b$ is Biot coefficient, $\rho g$ is gravity term, $q$ is the flow rate, $C_{g}$ is gas compressibility, $D_{\mathrm{g}}$ is gas diffusivity constant. The authors solved the complex problem using a numerical simulation approach and the investigation revealed that although 
stress reduces the overall gas production when compared with unstressed formation; however, the organic-rich rock had a higher cumulative gas production compared to rock with the absence of Total Organic Content (TOC). In addition, the authors recognized the effect of the choice of correlation on the reservoir performance dependency on stress and TOC (Aybar, 2014; Cho et al., 2013; Ozkan et al., 2010; Raghavan and Chin, 2004; Sullivan et al., 2006). In general, effective permeability, $\bar{k}$ in a fractured reservoir is $\bar{k}=k_{m}+k_{f}$, where, $k_{m}$ is the matrix permeability and $k_{f}$ is the fracture permeability. In addition to the desorption and diffusion equation, the authors coupled the geo-mechanical effects with the flow; given that the summation of the forces acting in all direction of the rock body in terms of overburden and effective stress of the organic-rich rock is zero (i.e., the body is at equilibrium).

\subsubsection{Pore filling models: The Dubinin-Radushkevich (DR) model and Dubinin-Astakhov (DA) model}

Pore-filling models assume that the adsorption mechanism in nano and micropores is as a result of the volume filling of pores and not the formation single or multi-layers (Astakhov and Dubinin, 1971). The Dubinin-Radushkevich (D-R) and Dubinin-Astakhov (D-A) equations were developed based on the theory of characteristic curved proposed by Polanyi (Gil and Grange, 1996). The authors argue that though porous adsorbents may contain varieties of pore sizes, the micropores are the key determinants of gas adsorption. The D-R equation is given as (Kapoor et al., 1989)

$$
\theta=\exp \left[-\left(\frac{A}{\beta E}\right)^{2}\right]=\exp \left[-\left(\frac{R T}{\beta E} \ln \frac{P_{o}}{P}\right)^{2}\right],
$$

where $\theta$ is the relative adsorption, $A$ is the adsorption potential, $E$ is the characteristic energy of adsorption (cal $/ \mathrm{mol}), \beta$ is the affinity coefficient, $R$ is the gas constant and $P$ is the pressure. The D-A model is given as (Kapoor et al., 1989)

$$
\theta=\exp \left[-\left(\frac{A}{\beta E}\right)^{n}\right]=\exp \left[-\left(\frac{R T}{\beta E} \ln \frac{P_{o}}{P}\right)^{n}\right] .
$$

These equations can be used for modeling adsorption studies at different temperatures (Fianu et al., 2019b). The D-R and D-A models were developed for a homogenous pore structure (Hutson and Yang, 1997). Huber et al. (1978), extended the D-R model to account for non-homogeneous micropores. Further extension by Kapoor et al. (1989) allows for the prediction of multicomponent equilibria (Kapoor and Yang, 1989).

\subsubsection{Brunauer-Emmett-Teller (BET) model}

The single-layer adsorption assumption by Langmuir results in the failure to model secondary phase adsorption which occurs when there are layers of adsorption. The BET model was developed to account for subsequent layers of adsorption near saturation conditions. When there is multilayer adsorption, each layer represents a different adsorption site, having distinct energy. An advantage of this model is that it allows for the computation of surface area (Brunauer et al., 1938). Unlike the Langmuir model, which is valid at low pressures, the BET model captures behavior at both low and high pressures.

The BET isotherm equation is given by

$$
\frac{P}{V\left(P_{o}-P\right)}=\frac{1}{V_{m}}+\frac{c-1}{V_{m} C} \frac{P}{P_{o}},
$$

where $V_{m}$ is the volume of gas adsorbed, $P_{o}$ is gas saturation pressure, $P$ is pressure and $c$ is constant.

\subsection{Single component vs. multicomponent models}

In single-component adsorption models, a single gas such as methane is used for adsorption studies. Natural gas from coal and shale is made up of different components, though methane may be abundant, with models assuming pure methane. The effect of the different gas components, regardless of their mole ratio play significant roles in the adsorption process and hence cannot be overlooked. Multicomponent adsorption models are the class of models that describe adsorption behavior of gas mixtures. Most of the adsorption isotherms described above deal with a single component gas adsorption. Under this section we review some of the more popular multicomponent models available.

\subsubsection{Multicomponent Langmuir model}

This model was developed as an extension of the Langmuir model for gas mixtures (Hall et al., 1994; Ruthven, 1984). The model accounts for the molar volume as well as the partial pressure of the components and is used in the prediction of adsorption equilibrium for mixtures based on their pure component isotherms.

The isotherm is defined as

$$
V_{a}=\sum_{i=1}^{n} \frac{V_{L i}\left(p_{g} y_{i}\right)}{P_{L i}+\sum_{j=1}^{n} \frac{1}{P_{L i}}\left(y_{j} p_{g}\right)},
$$

where $V_{\mathrm{a}}$ is the amount of adsorbed gas, $p_{g}$ are partial pressures, $y_{i}$ is mole fractions.

\subsubsection{MultiSite Occupancy Model (MSOM)}

The Langmuir model assumes no interaction between adsorbed molecules however, the MSOM model was developed to account for adsorption on multiple sites and multicomponent mixtures such as hydrocarbons (Nitta et al., 1984b). The MSOM model is derived for both single and multiple component adsorptions from a localized model in which the molecule occupies multiple site on a homogeneous surface.

The single component expression for MSOM on a homogeneous surface is given as

$$
\ln (n K P)=\ln \theta-n \ln (1-\theta)-n \theta u / k T .
$$

The multicomponent expression on a homogeneous surface is given as 
$\ln \left(n_{i} K_{i} P_{i}\right)=\ln \theta_{i}-n_{i} \ln \left(1-\sum_{j} \theta_{j}\right)-n_{i} \sum_{j} \theta_{j} u_{i j} / k T$.

where $n$ is the number of sites occupied by one molecule, $K$ is the adsorption equilibrium constant, $P$ is the pressure, $p$ is the partial pressure, $\theta$ is the surface coverage, $u$ is the molecular interaction parameter, $k$ is the Boltzmann constant, and $T$ is the temperature.

The MSOM model was further extended for adsorption on heterogeneous surfaces (Nitta et al., 1984a).

There have been several modifications to the MSOM model in the literature. This includes extensions proposed by Bai et al. (2003), Azizian and Bashiri (2009), and Romanielo et al. 2014.

\subsubsection{Ideal Adsorbed Solution Theory (IAST)}

The IAST is regarded as one of the fundamental models in adsorption science and can be used to describe the adsorption characteristics for ideal mixtures (Ahmadpour et al., 1998; Chen et al., 2011). The model was derived from thermodynamic theory. It models the adsorption equilibria of gas mixtures using pure component isotherms (Myers and Prausnitz, 1965). The IAST is the most commonly used method because of its reliability and ease as it uses only the pure-component adsorption isotherms to model the gas mixture adsorption equilibrium. There are three major assumptions to IAST model: (1) Adsorbate molecules in the mixture have equal access to the entire surface area of adsorbent; (2) Adsorbent is homogeneous; (3) Adsorbed phase is an ideal solution in which makes it analogous to Raoult's law (Walton and Sholl, 2015). With such as assumption, the partial pressure of the adsorbed phase can be computed using its mole fraction in the adsorbed phase and the pressure exerted as a pure component pressure at the same temperature and spreading pressure. Under IAST the spreading pressure for pure components can be calculated by

$$
\frac{\pi A}{R T}=\int_{0}^{p_{i}} \frac{n_{i}}{P_{i}} \mathrm{~d} P_{i}
$$

where $\pi$ is the spreading pressure. The spreading pressure is similar to the negative of surface tension and for adsorption its value is positive. The partial pressure for a constant temperature and spreading pressure can be calculated using an analog to Raoult's law as

$$
P_{i}=x_{i} p_{i}
$$

where $p_{i}$ is the partial pressure of pure component $i$. The total adsorbed amount can then be calculated as

$$
\frac{1}{n_{T}}=\sum_{i=1}^{N} \frac{x_{i}}{n_{i}^{0}}
$$

where $x_{i}$ is mole fraction of component $i, N$ is the total number of species. $n_{i}^{0}$ is the amount of component $i$ adsorbed at constant temperature and spreading pressure. Finally the adsorption of each pure species is calculated by

$$
n_{i}=x_{i} n_{T} .
$$

The major shortcoming of IAST is that it provides erroneous predictions for adsorbents with heterogeneous surfaces.

\subsubsection{Vacancy Solution Model (VSM)}

In the Vacancy Solution Model (VSM) proposed by Suwanayuen and Danner (1980a, 1980b), the adsorption surfaces are assumed to be occupied by an imaginary solvent, termed vacancy, where the gas and adsorbed phases may fill. The gas and adsorbed phases are considered as solutions of different adsorbate compositions in the vacancy. The adsorption of a gas mixture is then assumed to be an equilibrium between two vacancy solutions of different compositions. The non-ideality of the adsorbed gas is predicted using models of activity coefficient such as the Wilson and Flory-Huggins equation.

\section{Surfactant adsorption}

Surfactants like polymer are introduced into the reservoir to enhance production. While, polymers are useful in fluid mobility control, surfactants are used to reduce the capillary effect and interfacial tensions between the rock and the oil. A surfactant consists of both hydrophobic and hydrophilic parts which make the surfactant molecule susceptible to adsorption onto rock surfaces. Suresh et al. (2018) reported the applicability of nanoparticle to reduce surfactant adsorption unto the rock surface. This is due to the electrostatic repulsion induced by the nanoparticle which reduced the bridging polar heads of the surfactant. The presence of gases in the reservoir has also been reported to cause the adsorption of surfactants onto the rock surfaces as well as cause foam instability in enhanced oil recovery (Yin et al., 2009). Liu et al. (2006) reported surfactant adsorption in a surfactant-gas co-flooding operation with the aim of establishing a relationship between the critical foam concentration and the mobility improvement as well as its effect on reservoir wettability. The authors using a Commercial Surfactant (CD-1045 $5^{\mathrm{TM}}$ ) and an Indiana limestone sample and ran several cores flooding experiments with different flow conditions and concentration. Their findings revealed that the adsorption of the surfactant with or without the presence of gases remains the same and reduces the gas mobility. Furthermore, it improves the foam stability, yielding a stable flooding front and improved sweep efficiency. Adsorption and desorption test shows that the desorption was a much slower process that agrees with the literature.

Glover et al. (1979) using two surfactants in the volume ratios of 63:37 and 90:10 investigated the behavior of surfactants and their retention potential on the Barea sandstone sample using core flooding experiments. To obtain the retained surfactant, an arithmetic difference between the injection stream concentration and effluent stream concentration was used with the findings revealing the dependence 
of the retention process on water salinity and surfactant concentration. More so, a linear relationship is observed to exist between the retention and water salinity, thus, a trapping phenomenon at high concentration.

Surfactant is a chemical whose use and advantages have long been established in literature to alter the wettability of the rock and reduce the interfacial tension between immiscible fluids (Zhou et al., 2012). This has led to recovery increase but with a drawback of adsorption unto the rock surface which begs the question of its economic viability as an EOR option in the face of adsorption. Over the years, several surfactants have been tried on different reservoir systems with different mineralogy to quantify the degree of adsorption and suitability for enhanced oil recovery (Celik and Somasundaran, 1980; Cui et al., 2015; Meyers and Salter, 1980; Wang et al., 2015; Zhou et al., 2012). Debates have been ongoing for decades over the effect of surfactant/ $\mathrm{CO}_{2}$ co-injection for enhancing the oil recovery process and the effect of gas fractional flow on recovery. Yin et al. (2009) in a recent work demonstrated the effect of fractional gas flow rate using Barea sandstone core samples with Chaser CD1045 obtained from Chaser International. Series of experiments were conducted with $\mathrm{CO}_{2} / \mathrm{CD}, \mathrm{CO}_{2} /$ brine, and water flooding experiments as well as varying $\mathrm{CD}$ concentration, total gas, liquid flowrates and fractional gas ratio. The findings revealed that there exists a three-flow regime which is the single-phase zone, pseudo-single-phase zone and the high fractional gas zone. Gas mobility was observed to increase with an increase in fractional gas ratio in the single-phase gas zone, decrease with increase in the fractional gas fraction in the pseudo-single-phase zone and increases in the high fractional gas zone also revealing the existence of a critical gas fractional ratio at which the increase in mobility is dependent on. These phenomena are asserted to be due to limiting capillary pressure. Furthermore, total flow rate and permeability are identified to be the most dominant factors in the determination of the critical fractional gas rate to reduce foam mobility. More so, adsorption of surfactant is seen to be a fast process and the desorption is partially reversible and a slow process. However, its effect on recovery was not ascertained by the authors. Oil recovery is reported to increase even after $\mathrm{CO}_{2}$ and water flooding due to $\mathrm{CO}_{2} /$ surfactant injection and reverse showed no increase in recovery which qualifies the $\mathrm{CO}_{2} /$ surfactant injection as a good EOR technique.

Surfactant adsorption has been reported to be due to electrostatic interactions as well as influenced by the surfactant structure and mineralogy (Zhong et al., 2019). Mannhardt et al. (1994) assert that one way to control surfactant adsorption would be to mix it with anionic surfactants which has shown low adsorption tendencies with low salinity to moderate salinity brine systems. Trogus et al. (1977) studied the adsorption of anionic and nonionic surfactants in a dynamic and static adsorption experiment and revealed that the adsorption of nonionic surfactants increases sharply with the increase in concentration and attains a constant value which corresponds to the adsorbent maximum capacity which represents the critical micelle concentration, however, noted that the adsorption decreases with increase in solubility of the surfactant in water which is achieved by the addition of alcohol. On the other hand, the adsorption measurement of the anionic surfactant was difficult due to precipitation and high salinity. Furthermore, in modeling the process of adsorption, dispersion effect is observed to have negligible influence and the anionic surfactant has preferential adsorption on kaolin than on Barea sandstone, which is attributed to the electric nature of the rocks. Contrary to popular belief on the use of cationic surfactants and their propensity to cause adsorption in sandstone reservoirs, the opposite is observed in carbonates (Celik and Somasundaran, 1980). Tabatabal et al. (1993) reported a decrease in cationic surfactant adsorption on carbonate core and alluded that it is due to the lattice charge of the mineral surface.

Tumba et al. (2019) based on previous suggestions of co-injecting surfactant with additives to prevent adsorption utilized lignin as an additive to pervert adsorption on clay which is available in reservoirs. Sodium dodecyl sulfate (SDS) and 4-octylphenol polyethoxylated (TX-100) adsorption were investigated with clay (kaolinite, montmorillonite, illite, and quartz) using lignin as an additive and the results show interesting findings. Mineralogy is observed to be a controlling factor as earlier reported in the literature. Quartz was observed to have the least adsorption compared to the other clay minerals due to the hydrogen bond formation by the surface group of quartz sand and makes the adsorption by other mechanisms impossible. Adsorption of SDS is seen to be higher compared to TX-100 due to hydrophobic interactions of the hydrocarbon in the nonionic surfactant. Adsorption on montmorillonite and illite is dimmed impossible due to the negative charge of the clay surface which repels the anionic surfactant. So conclusively, the anionic surfactant is more promising compared to the nonionic surfactant in oil recovery.

Bhuyan et al. (1990) modeled high pH surfactant flooding. They modeled adsorption using a Langmuir type adsorption isotherm given as

$$
\left(C_{s}^{t}\right)_{\mathrm{abs}}=\frac{a C_{s}^{t}}{1+b C_{s}^{t}},
$$

where, $\left(C_{s}^{t}\right)_{\text {abs }}$ is the concentration of surfactant adsorbed, $C_{s}^{t}$ is the concentration of surfactant, and $a$ and $b$ are constants of the isotherm. With reference to equation (38),

$$
\begin{gathered}
a=a_{1}+a_{2} C_{\mathrm{se}} \text { for } \mathrm{pH} \leq(\mathrm{pH})_{c} \\
a=\left(a_{1}+a_{2} C_{\mathrm{se}}\right)\left[1-\frac{\mathrm{pH}-(\mathrm{pH})_{c}}{(\mathrm{pH})_{t}-(\mathrm{pH})_{c}}\right] \text { for }(\mathrm{pH})_{t} \geq \mathrm{pH}>(\mathrm{pH})_{c}, \\
a=0 \text { for } \mathrm{pH}>(\mathrm{pH})_{t},
\end{gathered}
$$

where, $a_{1}$ and $a_{2}$ are constants of isotherm, $(\mathrm{pH})_{c}$ is $\mathrm{pH}$ below which adsorption of surfactant is not a function of $\mathrm{pH}$, and $(\mathrm{pH})_{t}$ is the $\mathrm{pH}$ above which adsorption of surfactant is negligibly small. All these terms are determined experimentally, $C_{\text {se }}$ is the effective salinity. 
Grigg and Mikhalin (2007) studied the effect of flow conditions on the anionic surfactant adsorption to quantify the effect of the test system on adsorption kinetics using the batch test on crushed samples, flow test and non-flow dynamics experiments. Similar adsorption isotherm was observed for both the crushed sample and the dynamic experiments with no flow and less adsorption in a flow dynamic experiment which is due to flow velocity. Even though the authors stated that equilibrium kinetics was studied, there was no justification for reports of values or kinetic models to show that. Thus, the question of surfactant adsorption kinetics remains a further area for research.

Ramirez et al. (1980) reported that in the conventional adsorption kinetic models, the desorption rates are misrepresented and assert that the adsorption kinetic rate is five times faster than the equilibrium desorption kinetic rate. Bai et al. (2005) based on an earlier report about how fast the adsorption kinetics was compared to the desorption kinetic rate conducted series of experiments to establish a rate dependent adsorption/desorption kinetic equation using Barea sandstone and CD 1045 chaser surfactant supplied by Chaser International. The authors reported an early rapid adsorption trend followed by a slow period of adsorption and the adsorption kinetics to follow pseudosecond-order kinetics given in equation (42):

$$
\frac{\mathrm{d} q_{t}}{\mathrm{~d} t}=k_{a 2}\left(q_{e}-q_{t}\right)^{2}
$$

Upon integrating and rearranging, we have equation (43):

$$
\frac{t}{q_{t}}=\frac{1}{q_{t}} t+\frac{1}{k_{a 2} \cdot q_{e}^{2}}
$$

Thus, a plot of $\left(t / q_{t}\right)$ versus $t$ gives a slope and intercepts of $\left(1 / q_{e}\right)$ and $1 /\left(k_{a 2} q_{e}^{2}\right)$ respectively. The desorption kinetics is also seen to follow similar pseudo-second-order kinetics and is described in equation (44):

$$
\frac{1}{q_{t}-q_{r}}=-k_{d 2} t+\frac{1}{q_{i}-q_{r}} .
$$

Good agreement was achieved with the experimental data and to further the kinetics, a relationship between the kinetic coefficients and initial concentration is reported as in equation. This is to enable the determination of adsorption rate in a short time interval to avoid waiting for days for equilibration. However, the temperature dependence of the kinetics was not well established:

$$
\left\{\begin{array}{c}
k_{a 2}=-8.93 E-04 C_{i}+1.34 \text { for } \quad \mathrm{C}_{i}<1200(\mathrm{mg} / \mathrm{L}) \\
k_{a 2}=-1.04 E-04 C_{i}+0.401 \text { for } \quad \mathrm{C}_{i}>1200(\mathrm{mg} / \mathrm{L})
\end{array},\right.
$$

where $q_{t}$ is the adsorption density a time, $t$ is time, $k_{a 2}$ is the pseudo-second-order kinetic coefficient of adsorption, $q_{e}$ adsorption density at equilibrium, $\mathrm{C}_{i}$ initial concentration, $k_{d 2}$ pseudo-second-order kinetic coefficient of desorption, and $q_{r}$ is residual adsorption density.

In combating the problems of surfactant adsorption in the reservoir, many researchers have proposed different techniques which include the injection of low concentration of surfactant, pre-flushing with a sacrificial chemical or co-injection of surfactant with a chemical with similar competitive attributes to site interactions. Polyacrylate is been identified as a good sacrificial agent hand that presents a better performance in limestone and sandstone systems. It is also independent of the surfactant used and increases in molecular weight results to reduce the surfactant adsorption to rock surface until the critical molecular weight beyond which no additional effect is derived (ShamsiJazeyi et al., 2013). This presents a solution to the drawback of the use of sodium-based surfactants which react with anhydrides in rocks. Krumrine et al. (1982) reported the significant reduction in surfactant adsorption by the addition of sodium silicate, sodium carbonate and sodium tripolyphosphate and stated that the alkaline surfactant is useful only when the optimal $\mathrm{pH}$ and salinity can be determined for their implementation as well concentration range within which increase in recovery can be ascertained.

Ahmadi et al. (2012) studied the adsorption kinetics and equilibrium of a novel surfactant (Glycyrrhiza Glabra). They compared the adsorption data using different adsorption equilibrium and kinetics models and concluded that the Langmuir isotherm best suited the equilibrium data. The different isotherms they used were Langmuir, Freundlich, Temkin, and linear. Table 3 lists the correlations and the fitting parameters calculated by the authors.

Ahmadi and Shadizadeh (2015) performed a similar study on the adsorption of a surfactant extracted from the leaves of Zyziphus Spina Christi on Shale rocks and concluded that Freundlich isotherm gave the best match with the results.

Cui et al. (2015) investigated the use of switchable cationic surfactant adsorption using zeta potential measurement on dolomite, calcite, and Kaoline at high and low $\mathrm{CO}_{2}$ injection pressures. The anionic surfactant (tertiary amine Ethomeen $\mathrm{C}_{12}$ ) upon equilibration in brine switches to a cation at high $\mathrm{CO}_{2}$ pressure and a $\mathrm{pH}$ of 4 . This unique quality of the surfactant led to a reduction in adsorption however, the presence of clay and silica presents a drawback. More so, the presence of divalent and trivalent cations reduces dissolution of calcite or dolomite at high pressure however presents a challenge of a rise in $\mathrm{pH}$ which increases adsorption (Meyers and Salter, 1980). Contrary to the conventional method of adsorbed surfactant measuring technique which involves measuring concentration changes, Zhou et al. (2005) developed a novel technique called sandwashing technique which allows the determination of adsorbed surfactant on the sand face and at an oil-water interface in the presence of oil. The technique involves the equilibration of the sand or oil/sand/surfactant system for a minimum of 30 days and extraction using the azeotropic mixture in the Soxhlet apparatus. Findings from the work revealed the dependence of surfactant adsorption on brine salinity as well as the surface charges of the rock which leads to electrostatic interactions. Surfactant at low concentration and presence of alkali is observed to reduce the adsorption of surfactants and the presence of oil leads to emulsion formation which reduces the surfactant adsorption to the sand face.

Wang et al. (2015) investigated the effect of polymer on surfactant adsorption in an experiment to ascertain the 
degree of adsorption using the polymer as a pre-flush agent. An average of $0.163 \mathrm{mg} / \mathrm{g}$-rock of surfactant was adsorbed when surfactant alone was injected into the sandstone sample, with a reduction of $51.3 \%$ in the amount of adsorbed surfactant when the polymer was used as a preflush. This is to say that the polymer was used as a sacrificial chemical to avoid the loss of surfactant. However, in an economic sense, a polymer is not cheap and as well adds to the cost of operation and may as well impair the permeability of the rock. So even though the presented case seems reasonable, it may lead to an uneconomically feasible project.

The economics of surfactant injection implementation does not only significantly depend on the amount of surfactant needed but also on the rate of loss of surfactant within the reservoir. Even though the potential for adsorption reduction of surfactants has been shown in the literature (Tumba et al., 2019), its economic evaluation remains a question. Tsau et al. (2000) evaluated the economic impact of the use of lignosulfonate as a sacrificial chemical in surfactant flooding and based on a reduction of surfactant adsorption of $24-60 \%$ and $15-29 \%$ in Barea sandstone and Indiana limestone, different implementation schemes can be designed. The authors concluded that the injection of lignosulfonate as a pre-flush is more economical than co-injection with the surfactant, however, no economic model or use of fiscal systems was shown to provide a basis for such argument. For the effect evaluation of a chemical in view of economics, a fiscal system must be used in the evaluation and benchmarked against alternatives before a conclusive decision can be justified. Adsorption of surfactant is not peculiar to conventional reservoirs alone but also occurs in shales as well. Mirchi et al. (2016) studied surfactant adsorption in shale and concluded that surfactant adsorption phenomena exist in shales as well and the adsorption isotherm follows the Langmuir isotherm.

\section{Conclusion}

In this study, we discussed the adsorption of nanoparticles, polymers, gas, and surfactant in porous media. Special attention was given to understanding the different modeling techniques currently available to model adsorption. Firstly, for the adsorption of nanoparticles on porous media, it was concluded that the rate of adsorption increased with the flowrate but decreased with the presence of clay ( $\mathrm{Yu}$ et al., 2012; Zhang et al., 2015). It was also concluded that adsorption of nanoparticles, and particle retention in pores of the porous media are the major contributors accounting for the loss of nanoparticles. It is therefore important to consider these factors when modeling flow and transport of nanoparticles in porous media (Ju et al., 2012).

Secondly, the main factors affecting the polymer adsorption in porous media are the adhesion to the rock surface, trapping and particle entrainment. While modeling polymer adsorption it is essential to account for the reduction in permeability of the porous media. Langmuir isotherm is the most popular adsorption isotherm used to model adsorption of polymers on the reservoir rock surfaces (Braconnier et al., 2017; Khormali et al., 2018).

Thirdly, it is essential to accurately model gas adsorption in shales because $20-80 \%$ of shale gases are stored in adsorbed phases. Similar to polymer adsorption, Langmuir model is the most implemented model for the prediction of gas adsorption. Langmuir model however fails when layers of adsorption are present, in this scenario it is essential to utilize a multilayer model such as the BET isotherm. In the presence of multicomponent gases, the adsorption behavior can be modeled by MSOM model or the IAST model.

Finally, surfactant adsorption can be modeled by different isotherms such as Langmuir, Freundlich, Temkin and Linear models. A detailed study was performed on matching the isotherms to the experimental results for two different surfactants: Glycyrrhiza Glabra on carbonate cores (Ahmadi et al., 2012) and a surfactant obtained from Zyziphus Spina Christi on Shale rocks (Ahmadi and Shadizadeh, 2015). It was concluded that the Langmuir model gave the best match for the former case whereas the Freundlich model gave the best match for the latter case.

Acknowledgments. The authors acknowledge the support provided by the College of Petroleum Engineering and Geosciences (CPG) at King Fahd University of Petroleum and Minerals, Saudi Arabia for access to its educational resources used in this study. The authors also express their sincere gratitude towards the editor and the anonymous reviewers for their comments and suggestions.

\section{References}

Abdelfatah E.R., Kang K., Pournik M., Shiau B., Harwell J., Haroun M.R., Rahman M.M. (2017) Study of nanoparticle adsorption and release in porous media based on the DLVO theory, in: SPE Latin America and Caribbean Petroleum Engineering Conference, 17-19 May, Buenos Aires, Argentina. https://doi.org/10.2118/185484-ms.

Abraham W.H. (1966) Transient polycondensation calculationsan analytical solution, Chem. Eng. Sci. 21, 327-336. https:// doi.org/10.1016/0009-2509(66)85025-X.

Agarwal V.K. (2012) Stability study of important Metal Organic Frameworks (MOFs) and a review on their gas adsorption properties.

Ahmadi M.A., Shadizadeh S.R. (2015) Experimental investigation of a natural surfactant adsorption on shale-sandstone reservoir rocks: Static and dynamic conditions, Fuel 159, 15-26. https://doi.org/10.1016/j.fuel.2015.06.035.

Ahmadi M.A., Zendehboudi S., Shafiei A., James L. (2012) Nonionic surfactant for enhanced oil recovery from carbonates: Adsorption kinetics and equilibrium, Ind. Eng. Chem. Res. 51, 9894-9905. https://doi.org/10.1021/ie300269c.

Ahmadpour A., Wang K., Do D.D. (1998) Comparison of models on the prediction of binary equilibrium data of activated carbons, AIChE J. 44, 740-752. https://doi.org/10.1002/ aic.690440322.

An C., Fang Y., Liu S., Alfi M., Yan B., Wang Y., Killough J. (2017) Impacts of matrix shrinkage and stress changes on 
permeability and gas production of organic-rich shale reservoirs, in: Soc. Pet. Eng. - SPE Reservoir Characterisation and Simulation Conference and Exhibition 2017, pp. 537-555.

An C., Killough J., Mi L. (2019) Stress-dependent permeability of organic-rich shale reservoirs: Impacts of stress changes and matrix shrinkage, J. Pet. Sci. Eng. 172, 1034-1047. https:// doi.org/10.1016/j.petrol.2018.09.011.

Anderson R.B. (1946) Modifications of the Brunauer, Emmett and Teller equation, J. Am. Chem. Soc. 68, 686-691. https:// doi.org/10.1021/ja01208a049.

Arain Z.U.A., Al-Anssari S., Ali M., Memon S., Bhatti M.A., Lagat C., Sarmadivaleh M. (2019) Reversible and irreversible adsorption of bare and hybrid silica nanoparticles onto carbonate surface at reservoir condition, Petroleum. https://doi.org/ 10.1016/j.petlm.2019.09.001.

Aranovich G.L. (1991) New polymolecular adsorption isotherm, J. Colloid Interface Sci. 141, 30-43. https://doi.org/10.1016/ 0021-9797(91)90299-N.

Astakhov V.A., Dubinin M.M. (1971) Development of the concept of volume filling of micropores in the adsorption of gases and vapors by microporous adsorbents - Communication 3. Zeolites with large cavities and a substantial number of adsorption centers, Bull. Acad. Sci. USSR Div. Chem. Sci. 20, 13-16. https://doi.org/10.1007/BF00849309.

Ayawei N., Ebelegi A., Wankasi D. (2017) Modelling and interpretation of adsorption isotherms, J. Chem. 2017, 3039817. https://doi.org/10.1155/2017/3039817.

Aybar U. (2014) Investigation of analytical models incorporating geomechanical effects on production performance of hydraulically and naturally fractured unconventional reservoirs, Geology.

Azizian S., Bashiri H. (2009) A new isotherm for multisite occupancy adsorption of binary gaseous mixtures, Langmuir 25, 2309-2312. https://doi.org/10.1021/la803675h.

Bae J.S., Bhatia S.K. (2006) High-pressure adsorption of methane and carbon dioxide on coal, Energy and Fuels 20 , 2599-2607. https://doi.org/10.1021/ef060318y.

Bai B., Grigg R.B., Liu Y., Zeng Z. (2005) Adsorption kinetics of surfactant used in $\mathrm{CO}_{2}$-Foam flooding onto berea sandstone, Proc. - SPE Annu. Tech. Conf. Exhib. 1951-1957 Society of Petroleum Engineers. https://doi.org/10.2523/95920-ms.

Bai R., Deng J., Yang R.T. (2003) Improved multisite langmuir model for mixture adsorption using multiregion adsorption theory, Langmuir 19, 2776-2781. https://doi.org/10.1021/ la020838v.

Belhaj A.F., Elraies K.A., Mahmood S.M., Zulkifli N.N., Akbari S., Hussien O.S.E. (2020) The effect of surfactant concentration, salinity, temperature, and $\mathrm{pH}$ on surfactant adsorption for chemical enhanced oil recovery: a review, J. Pet. Explor. Prod. Technol. 10, 125-137. https://doi.org/10.1007/s13202019-0685-y.

Bertier P., Schweinar K., Stanjek H., Ghanizadeh A., Clarkson C.R., Busch A., Kampman N., Prinz D., Amann-Hildenbrand A., Krooss B.M., Pipich V. (2016) On the use and abuse of $\mathrm{N}_{2}$ physisorption for the characterization of the pore structure of shales, Fill. Gaps - from Microsc. Pore Struct. to Transp. Prop. Shales 151-161. https://doi.org/10.1346/cms-wls-21-12.

Bhuyan D., Lake L.W., Pope G.A. (1990) Mathematical Modeling of High-pH Chemical Flooding, SPE Reserv. Eng. 5, 213-220. https://doi.org/10.2118/17398-PA.

Braconnier B., Preux C., Flauraud É., Tran Q.H., Berthon C. (2017) An analysis of physical models and numerical schemes for polymer flooding simulations, Comput. Geosci. 21, 12671279. https://doi.org/10.1007/s10596-017-9637-0.
Brunauer S. (1943) The Adsorption of Gases and Vapors. Volume I: Physical Adsorption, Princeton University Press.

Brunauer S., Deming L.S., Deming W.E., Teller E. (1940) On a theory of the van der Waals adsorption of gases, J. Am. Chem. Soc. 62, 1723-1732. https://doi.org/10.1021/ja01864a025.

Brunauer S., Emmett P.H., Teller E. (1938) Adsorption of gases in multimolecular layers, J. Am. Chem. Soc. 60, 309-319. https://doi.org/10.1021/ja01269a023.

Burcik E.J. (1965) A note on the flow behaviour of polyacrylamide solutions in porous media, Prod. Mon. 29, 6 .

Bustin R.M., Bustin A.M.M., Cui X., Ross D.J.K., Pathi V.S.M. (2008) Impact of shale properties on pore structure and storage characteristics, in: Society of Petroleum Engineers Shale Gas Production Conference, 2008, pp. 32-59. https:// doi.org/10.2118/119892-ms.

Celik M., Somasundaran P. (1980) Wettability of reservoir minerals by flotation and correlation with surfactant adsorption, in: SPE Oilfield and Geothermal Chemistry Symposium, 28-30 May, Stanford, California, Society of Petroleum Engineers. https://doi.org/10.2118/9002-MS.

Chen J., Loo L.S., Wang K. (2011) An Ideal Absorbed Solution Theory (IAST) study of adsorption equilibria of binary mixtures of methane and ethane on a templated carbon, J. Chem. Eng. Data 56, 1209-1212. https://doi.org/10.1021/je101099c.

Chen L., Jiang Z., Liu K., Ji W., Wang P., Gao F., Hu T. (2017) Application of Langmuir and Dubinin-Radushkevich models to estimate methane sorption capacity on two shale samples from the Upper Triassic Chang 7 Member in the southeastern Ordos Basin, China. Energy Explor. Exploit. 35, 122-144. https://doi.org/10.1177/0144598716684309.

Cheraghian G., Khalili Nezhad S.S., Kamari M., Hemmati M., Masihi M., Bazgir S. (2014) Adsorption polymer on reservoir rock and role of the nanoparticles, clay and $\mathrm{SiO}_{2}$, Int. Nano Lett. 4, 114. https://doi.org/10.1007/s40089-014-0114-7.

Cho Y., Apaydin O.G., Ozkan E. (2013) Pressure-dependent natural-fracture permeability in shale and its effect on shalegas well production, SPE Reserv. Eval. Eng. 16, 216-228. https://doi.org/10.2118/159801-PA.

Christopher R.H., Middleman S. (1965) Power-law flow through a packed tube, Ind. Eng. Chem. Fundam. 4, 422-426. https:// doi.org/10.1021/i160016a011.

Cohen Y., Christ F.R. (1986) Polymer retention and adsorption in the flow of polymer solutions through porous media, SPE Reserv. Eng. Soc. Pet. Eng. 1, 113-118. https://doi.org/ 10.2118/12942-PA.

Cui L., Ma K., Abdala A.A., Dhabi A., Lu L.J., Tanakov I., Biswal S.L., Hirasaki G.J. (2015) Adsorption of a switchable cationic surfactant on natural carbonate minerals, SPE J. 70-78. https://doi.org/10.2118/169040-pa.

Curbelo F.D.S., Garnica A.I.C., Leite D.F.Q., Carvalho A.B., Silva R.R., Paiva E.M. (2020) Study of Enhanced Oil Recovery and Adsorption Using Glycerol in Surfactant Solution, Energies 13, 3135. https://doi.org/10.3390/en13123135.

Curtis M.E., Ambrose R.J., Sondergeld C.H., Rai C.S. (2010) Structural characterization of gas shales on the micro- and nano-scales, in: Canadian Unconventional Resources and International Petroleum Conference, 19-21 October, Calgary, Alberta, Canada, Society of Petroleum Engineers, pp. 19331947. https://doi.org/10.2118/137693-ms.

Dang T.Q.C., Chen Z., Nguyen T.B.N., Bae W. (2014) Investigation of isotherm polymer adsorption in porous media, Pet. Sci. Technol. 32, 1626-1640. https://doi.org/10.1080/10916466. 2010.547910 . 
Dauben D.L., Menzie D.E. (1967) Flow of polymer solutions through porous media, J. Pet. Technol. 19, 1065-1073. https://doi.org/10.2118/1688-PA.

Dawson R., Lantz R.B. (1972) Inaccessible pore volume in polymer flooding, Soc. Pet. Eng. J. 12, 448-452. https://doi. org/10.2118/3522-PA.

de Boer J.H. (1953) The dynamical character of adsorption, Clarendon Press, Oxford.

Deem R.L., Ali S.M.F. (1968) Adsorption and Flow of Multiple Tracers in Porous Media, J. Can. Pet. Technol. 7, 60-65. https://doi.org/10.2118/68-02-06.

Ding W., Liu X., Song L., Li Q., Zhu Q., Zhu H., Hu F., Luo Y., Zhu L., Li H. (2015) An approach to estimate the position of the shear plane for colloidal particles in an electrophoresis experiment, Surf. Sci. 632, 50-59. https://doi.org/10.1016/j.susc. 2014.08.024.

Dominguez J.G., Willhite G.P. (1977) Retention and flow characteristics of polymer solutions in porous media, Soc. Pet. Eng. J. 17, 111-121. https://doi.org/10.2118/5835-PA.

Dubinin M.M., Radushkevich L.V. (1947) Equation of the characteristic curve of activated charcoal, Proc. Acad. Sci. USSR Phys. Chem. Sect. 55, 331-337.

Fianu J., Gholinezhad J., Hassan M. (2019a) Comparison of single, binary and temperature-dependent adsorption models based on error function analysis, J. Oil Gas Petrochem. Sci. 2, 77-91. https://doi.org/10.30881/jogps.00027.

Fianu J., Gholinezhad J., Hassan M. (2019b) Application of temperature-dependent adsorption models in material balance calculations for unconventional gas reservoirs, Heliyon 5, e01721. https://doi.org/10.1016/j.heliyon.2019.e01721.

Flory P.J. (1953) Principles of polymer chemistry, Cornell University Press. https://doi.org/10.1126/science.119.3095.555-a.

Freundlich H. (1909) Kapillarchemie, eine Darstellung der Chemie der Kolloide und verwandter Gebiete, Akademische Verlagsgesellschaft.

Fritz W., Schluender E.U. (1974) Simultaneous adsorption equilibria of organic solutes in dilute aqueous solutions on activated carbon, Chem. Eng. Sci. 29, 1279-1282. https://doi. org/10.1016/0009-2509(74)80128-4.

Gil A., Grange P. (1996) Application of the DubininRadushkevich and Dubinin-Astakhov equations in the characterization of microporous solids, Colloids Surf. A Physicochem. Eng. Asp. 113, 39-50. https://doi.org/10.1016/0927-7757(96) 81455-5.

Glover C.J., Puerto M.C., Maerker J.M., Sandvik E.L. (1979) Surfactant phase behavior and retention in porous media, Soc. Pet. Eng. AIME J. 19, 183-193.

Gogarty W.B. (1967) Mobility Control With Polymer Solutions, Soc. Pet. Eng. J. 7, 161-173. https://doi.org/10.2118/ 1566-b.

Grigg R.B., Mikhalin A.A. (2007) Effects of flow conditions and surfactant availability on adsorption, in: Proceedings - SPE International Symposium on Oilfield Chemistry, pp. 450-456. https://doi.org/10.2523/106205-ms.

Gruesbeck C., Collins R.E. (1982) Entrainment and deposition of fine particles in porous media, Soc. Pet. Eng. J. 22, 847-856. https://doi.org/10.2118/8430-PA.

Guggenheim E. (1966) Application of statistical mechanics, Clarendon Press/Clarendon University Press, London.

Guzman K.A.D., Finnegan M.P., Banfield J.F. (2006) Influence of surface potential on aggregation and transport of titania nanoparticles, Environ. Sci. Technol. 40, 7688-7693. https:// doi.org/10.1021/es060847g.
Hall F.E., Chunhe Z., Gasem K.A.M., Robinson R.L., Dan Y. (1994) Adsorption of pure methane, nitrogen, and carbon dioxide and their binary mixtures on wet fruitland coal, in: SPE Eastern Regional Meeting, Society of Petroleum Engineers. https://doi.org/10.2118/29194-MS.

Halsey G. (1952) The Role of Surface Heterogeneity in Adsorption, Adv. Catal. 4, 259-269. https://doi.org/10.1016/S03600564(08)60616-1.

Hematfar V., Maini B.B., Chen Z. (2013) Experimental investigation of the impact of asphaltene adsorption on two phase flow in porous media, SPE - Eur. Form. Damage Conf. Proceedings, EFDC 2, 947-956.

Hill A. (1910) The possible effects of the aggregation of the molecules of hæmoglobin on its dissociation curves, BibSonomy J. Physiol 40, i-vii.

Hirasaki G.J., Pope G.A. (1974) Analysis of factors influencing mobility and adsorption in the flow of polymer solution through porous media, Soc. Pet. Eng. J. 14, 337-346. https:// doi.org/10.2118/4026-PA.

Huan-Zhi Z., Yan-Qing H. (2010) Resource potential and development status of global shale, Gas Oil Forum 6, 53-59.

Huber U., Stoeckli F., Houriet J.P. (1978) A generalization of the Dubinin-Radushkevich equation for the filling of heterogeneous micropore systems in strongly activated carbons, J. Colloid Interface Sci. 67, 195-203. https://doi.org/10.1016/0021-9797 (78)90002-4.

Hutson N.D., Yang R.T. (1997) Theoretical basis for the Dubinin-Radushkevitch (D-R) adsorption isotherm equation, Adsorption 3, 189-195. https://doi.org/10.1007/BF01650130.

Idris M.N., Kadafur I.B. (2015) Experimental studies on selected nano-particles using infrared spectrometry, Analysis 1, 124-137.

Jennings R.R., Rogers J.H., West T.J. (1971) Factors influencing mobility control by polymer solutions, J. Pet. Technol. 23, 391-401. https://doi.org/10.2118/2867-PA.

Joekar-Niasar V., Schreyer L., Sedighi M., Icardi M., Huyghe J. (2019) Coupled processes in charged porous media: from theory to applications, Transp. Porous Media 32, 183-214. https://doi.org/10.1007/s11242-019-01257-3.

Ju B., Fan T. (2009) Experimental study and mathematical model of nanoparticle transport in porous media, Powder Technol. 192, 195-202. https://doi.org/10.1016/j.powtec. 2008.12.017.

Ju B., Fan T., Li Z. (2012) Improving water injectivity and enhancing oil recovery by wettability control using nanopowders, J. Pet. Sci. Eng. 86-87, 206-216. https://doi.org/ 10.1016/j.petrol.2012.03.022.

Kapoor A., Ritter J.A., Yang R.T. (1989) On the DubininRadushkevich equation for adsorption in microporous solids in the Henry's Law Region, Langmuir 5, 1118-1121. https://doi. org/10.1021/la00088a043.

Kapoor A., Yang R.T. (1989) Correlation of equilibrium adsorption data of condensible vapours on porous adsorbents, Gas Sep. Purif. 3, 187-192. https://doi.org/10.1016/0950-4214(89) 80004-0.

Khan A.R., Al-Waheab I.R., Al-Haddad A. (1996) A generalized equation for adsorption isotherms for multi-component organic pollutants in dilute aqueous solution, Environ. Technol. (United Kingdom) 17, 13-23. https://doi.org/ 10.1080/09593331708616356.

Khormali A., Sharifov A.R., Torba D.I. (2018) Experimental and modeling study of asphaltene adsorption onto the reservoir rocks, Pet. Sci. Technol. 36, 1482-1489. https://doi.org/ 10.1080/10916466.2018.1496116. 
Krumrine P.H., Falcone J.S., Campbell T.C. (1982) Surfactant flooding -2 . The effect of alkaline additives on permeability and sweep efficiency, Soc. Pet. Eng. J. 22, 983-992. https:// doi.org/10.2118/9811-PA.

Landes S.H. (1961) Refinements in adsorption processing, in: Fall Meeting of the Society of Petroleum Engineers of AIME, 8-11 October, Dallas, Texas.

Langmuir I. (1918) The adsorption of gases on plane surfaces of glass, mica and platinum, J. Am. Chem. Soc. 40, 1361-1403. https://doi.org/10.1021/ja02242a004.

Li S., Hadia N.J., Lau H.C., Torsæter O., Stubbs L.P., Ng Q.H. (2018) Silica nanoparticles suspension for enhanced oil recovery: Stability behavior and flow visualization, in: Soc. Pet. Eng. SPE Eur. Featur. 80th EAGE Conf. Exhib. 2018. https://doi.org/10.2118/190802-ms.

Li S., Torsæter O. (2015) Experimental Investigation of the influence of nanoparticles adsorption and transport on wettability alteration for oil wet Berea sandstone, in: SPE Middle East Oil and Gas Show and Conference, MEOS, Proceedings, Society of Petroleum Engineers (SPE), pp. 229-244. https:// doi.org/10.2118/172539-ms.

Li S., Torsæter O., Lau H.C., Hadia N.J., Stubbs L.P. (2019) The impact of nanoparticle adsorption on transport and wettability alteration in water-wet berea sandstone: An experimental study, Front. Phys. 7, 74. https://doi.org/10.3389/fphy.2019. 00074.

Liu Y., Grigg R.B., Svec R.K. (2006) Foam mobility and adsorption in carbonate core, Proc. - SPE Symp. Improv. Oil Recover. 2, 737-744.

Lu X.C., Li F.C., Watson A.T. (1995) Adsorption measurements in devonian shales, Fuel 74, 4, 599-603.

Lowell S., Shields J.E., Lowell S., Shields J.E. (1991) Adsorption isotherms, in: Powder Surface Area and Porosity, Springer, Netherlands, pp. 11-13. https://doi.org/10.1007/978-94-0157955-1 3.

Mannhardt K., Novosad J.J., Jha K.N.N. (1994) Adsorption of foam-forming surfactants in Berea sandstone, J. Can. Pet. Technol. 33. https://doi.org/10.2118/94-02-04.

Marshall R.J., Metzner A.B. (1967) Flow of viscoelastic fluids through porous media, Ind. Eng. Chem. Fundam. 6, 393-400. https://doi.org/10.1021/i160023a012.

Masel R.I. (1996) Principles of adsorption and reaction on solid surfaces, John Wiley \& Sons Inc.

McMillan W.G., Teller E. (1951) The assumptions of the B.E.T. theory, J. Phys. Colloid Chem. 55, 17-20. https://doi.org/ $10.1021 / \mathrm{j} 150484 \mathrm{a} 003$.

Metzner A.B. (1977) Polymer solution and fiber suspension rheology and their relationship to turbulent drag reduction, Phys. Fluids 20, S145. https://doi.org/10.1063/1.861723.

Meyers K.O., Salter S.J. (1980) Effect of oil brine ratio on surfactant adsorption from microemulsions, Society of Petroleum Engineers of AIME, SPE.

Mirchi V., Saraji S., Goual L., Piri M. (2016) Experimental investigation of surfactant flooding in shale oil reservoirs: Dynamic interfacial tension, adsorption, and wettability, in: Society of Petroleum Engineers - SPE/AAPG/SEG Unconventional Resources Technology Conference, pp. 1-6. https:// doi.org/10.15530/urtec-2014-1913287.

Mungan N. (1969) Rheology and adsorption of aqueous polymer solutions, J. Can. Pet. Technol. 8, 45-50.

Myers A.L., Prausnitz J.M. (1965) Thermodynamics of mixed-gas adsorption, AIChE J. 11, 121-127. https://doi.org/10.1002/ aic. 690110125 .
Nitta T., Kuro-Oka M., Katayama T. (1984a) An adsorption isotherm of multi-site occupancy model for heterogeneous surface, J. Chem. Eng. Japan 17, 45-52. https://doi.org/ $10.1252 /$ jcej.17.45.

Nitta T., Shigetomi T., Kuro-Oka M., Katayama T. (1984b) An adsorption isotherm of multi-site occupancy model for homogeneous surface, J. Chem. Eng. Japan 17, 39-45. https://doi. org/10.1252/jcej.17.39.

Ogunberu A.L., Asghari K. (2005) Water permeability reduction under flow-induced polymer adsorption, J. Can. Pet. Technol. 44, 56-61. https://doi.org/10.2118/05-11-06.

Ohshima H. (1994) A simple expression for Henry's function for the retardation effect in electrophoresis of spherical colloidal particles, J. Colloid Interface Sci. 168, 1, 269-271. https://doi. org/10.1006/jcis.1994.1419.

Ozkan E., Raghavan R.S., Apaydin O.G. (2010) Modeling of fluid transfer from shale matrix to fracture network, in $S P E$ Annual Technical Conference and Exhibition, Society of Petroleum Engineers. https://doi.org/10.2118/134830-MS.

Radke C.J., Prausnitz J.M. (1972) Thermodynamics of multisolute adsorption from dilute liquid solutions, AIChE J. 18, 761-768. https://doi.org/10.1002/aic.690180417.

Raghavan R., Chin L.Y. (2004) Productivity changes in reservoirs with stress-dependent permeability, SPE Reserv. Eval. Eng. 7, 308-315. https://doi.org/10.2118/88870-PA.

Ramirez W., Shuler P., Friedman F. (1980) Convection, dispersion, and adsorption of surfactants in porous media, Soc. Pet. Eng. J. 20, 9. https://doi.org/10.2118/7951-PA.

Rani S., Prusty B.K., Padmanabhan E., Pal S.K. (2019) Applicability of various adsorption isotherm models on adsorption of methane and $\mathrm{CO}_{2}$ on Indian shales, Environ. Prog. Sustain. Energy 38, 13222. https://doi.org/10.1002/ep.13222.

Redlich O., Peterson D.L. (1959) A useful adsorption isotherm, $J$. Phys. Chem. 63, 1024. https://doi.org/10.1021/j150576a611.

Revil A., Schwaeger H., Cathles L.M., Manhardt P.D. (1999) Streaming potential in porous media: 2. Theory and application to geothermal systems, J. Geophys. Res. Solid Earth 104, 20033-20048. https://doi.org/10.1029/1999jb900090.

Rexer T.F.T., Benham M.J., Aplin A.C., Thomas K.M. (2013) Methane adsorption on shale under simulated geological temperature and pressure conditions, Energy Fuels 27, 3099-3109. https://doi.org/10.1021/ef400381v.

Romanielo L.L., Arvelos S., Tavares F.W., Rajagopal K. (2014) A modified multi-site occupancy model: evaluation of azeotropelike behavior in adsorption, Adsorption 21, 3-16. https:// doi.org/10.1007/s10450-014-9644-6.

Rowland F.W., Eirich F.R. (1966) Flow rates of polymer solutions through porous disks as a function of solute. I. method, J. Polym. Sci. Part A-1 Polym. Chem. 4, 2033-2040. https://doi.org/10.1002/pol.1966.150040901.

Ruthven D.M. (1984) Principles of adsorption \& adsorption processes, Wiley, New York.

Saadi R., Saadi Z., Fazaeli R., Fard N.E. (2015) Monolayer and multilayer adsorption isotherm models for sorption from aqueous media. Korean J. Chem. Eng. 32, 787-799. https:// doi.org/10.1007/s11814-015-0053-7.

Savins J.G. (1969) Non-newtonian flow through porous media, Ind. Eng. Chem. 61, 18-47. https://doi.org/10.1021/ie50718a005.

Sepehri M., Moradi B., Emamzadeh A., Mohammadi A.H. (2019) Experimental study and numerical modeling for enhancing oil recovery from carbonate reservoirs by nanoparticle flooding, Oil Gas Sci. Technol. - Rev. IFP Energies nouvelles 74, 5. https://doi.org/10.2516/ogst/2018080. 
ShamsiJazeyi H., Hirasaki G.J., Verduzco R. (2013) Sacrificial agent for reducing adsorption of anionic surfactants, in: Proceedings - SPE International Symposium on Oilfield Chemistry, pp. 214-229. https://doi.org/10.2118/164061-ms.

Sheng J.J. (2011) Modern chemical enhanced oil recovery, Elsevier Inc. https://doi.org/10.1016/C2009-0-20241-8.

Sips R. (1948) On the structure of a catalyst surface, J. Chem. Phys. 16, 490-495. https://doi.org/10.1063/1.1746922.

Smith F.W. (1970) The behavior of partially hydrolyzed polyacrylamide solutions in porous media, J. Pet. Technol. 22, 148-156. https://doi.org/10.2118/2422-pa.

Sorbie K.S. (1991) Introduction to polymer flooding, in: Polymer-Improved Oil Recovery, Springer, Netherlands, pp. 1-5. https://doi.org/10.1007/978-94-011-3044-8 1.

Sullivan R.B., Rushing J.A., Bachman R.C., Settari A., Conway M.W., Barree R.D. (2006) Evaluation of nonlinear fracture relative permeabilities and their impact on waterfrac performance in tight gas sands, in: Proc. - SPE Int. Symp. Form. Damage Control 2006, 15-17 February, Lafayette, Louisiana, USA, pp. 731-738.

Suresh R., Kuznetsov O., Agrawal D., Darugar Q., Khabashesku V. (2018) Reduction of surfactant adsorption in porous media using silica nanoparticles, Proc. Annu. Offshore Technol. Conf. 2, 984-992.

Suwanayuen S., Danner R.P. (1980a) Vacancy solution theory of adsorption from gas mixtures, AIChE J. 26, 76-83. https:// doi.org/10.1002/aic.690260113.

Suwanayuen S., Danner R.P. (1980b) A gas adsorption isotherm equation based on vacancy solution theory, AIChE J. 26, 68-76. https://doi.org/10.1002/aic.690260112.

Swenson H., Stadie N.P. (2019) Langmuir's theory of adsorption: A centennial review, Langmuir 35, 5409-5426. https:// doi.org/10.1021/acs.langmuir.9b00154.

Szabo M.T. (1975) Laboratory investigations of factors influencing polymer flood performance, Soc. Pet. Eng. AIME J. 15, 338-346. https://doi.org/10.2118/4669-PA.

Tabatabal A., Gonzalez M.V., Harwell J.H., Scamehorn J.F. (1993) Reducing surfactant adsorption in carbonate reservoirs, SPE Reserv. Eng. 8, 117-122. https://doi.org/10.2118/ 24105-pa.

Tan J., Weniger P., Krooss B., Merkel A., Horsfield B., Zhang J., Boreham C.J., Graas G.V., Tocher B.A. (2014) Shale gas potential of the major marine shale formations in the upper Yangtze platform, South China, Part II: methane sorption capacity, Fuel 129, 204-218.

Temkin M., Pyzhev V. (1940) Kinetics of ammonia synthesis on promoted iron catalysts, Acta Physicochimica URSS 12, 327-356.

Toth J. (1971) State equation of the solid gas interface layer, Acta Chim. (Academiae Sci) Hungaricae 69, 311-317.

Trogus F.J., Sophany T., Schechter R.S., Wade W.H. (1977) Static and dynamic adsorption of anionic and nonionic surfactants, Soc. Pet. Eng. AIME J. 17, 337-344. https:// doi.org/10.2118/6004-pa.

Tsau J.S., Syahputra A.E., Grigg R.B. (2000) Economic evaluation of surfactant adsorption in $\mathrm{CO}_{2}$ foam application, in: SPE/DOE Improved Oil Recovery Symposium, 3-5 April, Tulsa, Oklahoma. https://doi.org/10.2523/59365-ms.

Tumba J., Agi A., Gbadamosi A., Junin R., Abbas A., Rajaei K., Gbonhinbor J. (2019) Lignin as a potential additive for minimizing surfactant adsorption on clay minerals in different electrolyte concentration, in: Society of Petroleum Engineers - SPE Nigeria Annual International Conference and Exhibition 2019, NAIC 2019, pp. 1-23. https://doi.org/ 10.2118/198713-MS.

Volmer M.A., Mahnert P. (1925) Solution of solid substances in liquid surfaces and the characteristics of layers thus produced, Z. Phys. Chem 115, 253.

Walton K.S., Sholl D.S. (2015) Predicting multicomponent adsorption: 50 years of the ideal adsorbed solution theory, AIChE J. 61, 2757-2762. https://doi.org/10.1002/aic.14878.

Wang J., Han M., Fuseni A.B., Cao D. (2015) Surfactant adsorption in Surfactant-Polymer flooding for carbonate reservoirs, in: SPE Middle East Oil and Gas Show and Conference, MEOS Proceedings, pp. 1736-1746. https://doi. org/10.2118/172700-ms.

Wang W., Yuan B., Su Y., Wang K., Jiang M., Moghanloo R.G., Rui Z. (2016a) Nanoparticles adsorption, straining and detachment behavior and its effects on permeability of Berea cores: Analytical model and lab experiments, in: Proceedings - SPE Annual Technical Conference and Exhibition, Society of Petroleum Engineers (SPE). https:// doi.org/10.2118/181285-ms.

Wang Y., Zhu Y., Liu S., Zhang R. (2016b) Methane adsorption measurements and modeling for organic-rich marine shale samples, Fuel 172, 301-309. https://doi.org/10.1016/ j.fuel.2015. 12.074.

Wang Z., Li Y., Guo P., Meng W. (2016c) Analyzing the adaption of different adsorption models for describing the shale gas adsorption law, Chem. Eng. Technol. 39, 1921-1932. https://doi.org/10.1002/ceat.201500617.

White J. (2012) Computational fluid dynamics modelling and experimental study on a single silica gel type B, Model. Simul. Eng. 2012, 9. https://doi.org/10.1155/2012/598479.

Willhite G.P., Dominguez J.G. (1977) Mechanisms of polymer retention in porous media, in Improved Oil Recovery by Surfactant and Polymer Flooding, D.O. Shah, R.S. Schechter (eds), Academic Press Inc., pp. 511-554.

Xiao-Chun Lu, Li Fan-Chang, Watson A.T. (1995) Adsorption studies of natural gas storage in Devonian shales, SPE Form. Eval. 10, 109-113. https://doi.org/10.2118/26632-pa.

Yan B., Wang Y., Killough J.E. (2016) Beyond dual-porosity modeling for the simulation of complex flow mechanisms in shale reservoirs, Comput. Geosci. 20, 69-91. https://doi.org/ 10.1007/s10596-015-9548-x.

Yin G., Grigg R.B., Svec Y. (2009) Oil recovery and surfactant adsorption during $\mathrm{CO}_{2}$-foam flooding, Offshore Technol. Conf. Proc. 1, 106-119.

Yu J., An C., Mo D., Liu N., Lee R. (2012) Study of adsorption and transportation behavior of nanoparticles in three different porous media, Proc. - SPE Symp. Improv. Oil Recover. 1, pp. 311-323.

Yu W., Sepehrnoori K., Patzek T.W. (2016) Modeling gas adsorption in marcellus shale with Langmuir and bet isotherms. SPE J. Soc. Pet. Eng. 589-600. https://doi.org/10.2118/ 170801-PA.

Zhang J., Tang Y., Chen D. (2019) Prediction of methane adsorption content in continental coal-bearing shale reservoir using SLD model, Pet. Sci. Technol. 37, 1839-1845. https:// doi.org/10.1080/10916466.2019.1610773.

Zhang T. (2012) Modeling of nanoparticle transport in porous media. Transp. Porous Media 362.

Zhang T., Ellis G.S., Ruppel S.C., Milliken K., Yang R. (2012) Effect of organic-matter type and thermal maturity on methane adsorption in shale-gas systems, Org. Geochem. 47, $120-131$. 
Zhang T., Murphy M., Yu H., Bagaria H.G., Yoon K.Y., Nielson B.M., Bielawski C.W., Johnston K.P., Huh C., Bryant S.L. (2013) Investigation of nanoparticle adsorption during transport in porous media, in: Proceedings - SPE Annual Technical Conference and Exhibition, Society of Petroleum Engineers 3161-3180. https://doi.org/10.2118/166346-ms.

Zhang T., Murphy M.J., Yu H., Bagaria H.G., Yoon K.Y., Neilson B.M., Bielawski C.W., Johnston K.P., Huh C., Bryant S.L. (2015) Investigation of nanoparticle adsorption during transport in porous media, SPE J. 20, 667-677. https://doi. org $/ 10.2118 / 166346-P A$.

Zhong X., Pu H., Zhou Y., Zhao J.X. (2019) Static adsorption of surfactants on Bakken rock surfaces in high temperature, high salinity conditions, in: Proceedings - SPE International Symposium on Oilfield Chemistry, pp. 1-10. https://doi.org/ 10.2118/193589-ms.

Zhou W., Dong M., Liu Q., Xiao H. (2005) Experimental investigation of surfactant adsorption on sand and oil-water interface in heavy oil/water/sand systems, in: Canadian International Petroleum Conference, 7-9 June, Calgary, Alberta.

Zhou X., Han M., Fuseni A.B., Yousef A.A. (2012) Adsorptiondesorption of an amphoteric surfactant onto permeable carbonate rocks, SPE - DOE Improv. Oil Recover. Symp. Proc. 1, 552-572. https://doi.org/10.2118/153988-ms. 